\title{
Synthesis of the Entire Framework of Tartrolon B Utilizing a Silicon-Tethered Ring-Closing Metathesis Strategy
}

\author{
Yi Jin Kim and Daesung Lee* \\ Department of Chemistry, University of Wisconsin-Madison, Madison, WI 53706
}

\section{Supporting Information}

\section{Materials and Methods}

Commercially available chemicals were used without further purification. Tetrahydrofuran (THF) was freshly distilled from sodium/benzophenone, and dichloromethane $\left(\mathrm{CH}_{2} \mathrm{Cl}_{2}\right)$ was distilled from $\mathrm{CaH}_{2}$ under nitrogen atmosphere. Hexanes were also distilled prior to use. Flash chromatography was performed using silica gel (60 $\AA$ porosity, 32-63 $\mu \mathrm{m}$ particle size) from Sorbent Technologies. Reactions were monitored by thin layer chromatography (TLC) using $250 \mu \mathrm{m}$ E. Merck pre-coated silica gel $60 \mathrm{~F}_{254}$ (particle size $\left.40-63 \mu \mathrm{m}\right)$. ${ }^{1} \mathrm{H}$ NMR and ${ }^{13} \mathrm{C}$ NMR spectra were obtained on a Bruker AC-300, Varian MercuryPlus-300, or on a Varian UNITY-500 spectrometer. Chemical shifts are reported in $\delta$ values relative to an internal standard of tetramethylsilane (TMS). High-resolution mass spectra were obtained using Leu5enkephalin or erythromycin as a lock mass on an ESI-TOF spectrometer equipped with Z-spray and a reflectron.

\section{Experimental}

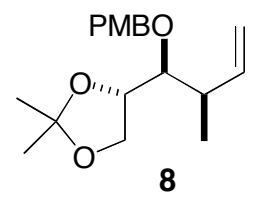

To a stirred mixture of potassium tert-butoxide $(5.0 \mathrm{~g}, 44.6 \mathrm{mmol})$, THF $(31 \mathrm{~mL})$, and cis-2-butene (10.0 mL, $89.3 \mathrm{mmol}), n$-butyllithium in hexanes $(2.5 \mathrm{M}, 44.6 \mathrm{mmol})$ was 
added slowly at $-78{ }^{\circ} \mathrm{C}$ under $\mathrm{N}_{2}$ atmosphere. After complete addition of $n$-butyllithium, the mixture was stirred at $-45^{\circ} \mathrm{C}$ for $10 \mathrm{~min}$. The resulting solution was cooled back to $-78{ }^{\circ} \mathrm{C}$, and to it was added drop-wise $(+)$-B-methoxydiisopinocampheylborane in ether $(1 \mathrm{M}, 53.6 \mathrm{mmol})$. After the reaction mixture was stirred at $-78{ }^{\circ} \mathrm{C}$ for $30 \mathrm{~min}, \mathrm{BF}_{3} \cdot \mathrm{OEt}_{2}$ $(8.0 \mathrm{~mL}, 67 \mathrm{mmol})$ was added dropwise. Then aldehyde $7(9.5 \mathrm{~g}, 73.0 \mathrm{mmol})$ was added drop-wise as a solution in $\mathrm{Et}_{2} \mathrm{O}$ at $-78{ }^{\circ} \mathrm{C}$. The mixture was stirred at this temperature for $3 \mathrm{~h}$ then treated with $41 \mathrm{~mL}$ of $3 \mathrm{M} \mathrm{NaOH}$ and $17 \mathrm{~mL} 30 \% \mathrm{H}_{2} \mathrm{O}_{2}$, and the contents were refluxed for $1 \mathrm{~h}$. The organic layer was separated and washed with water and brine, dried over $\mathrm{MgSO}_{4}$, filtered, and concentrated in vacuo. An inseparable mixture of the desired crotylation product and isopinocampheyl alcohol (ca. 1:2, 19.0g) was obtained after silica gel column chromatography (12:1 to $3: 1$ hexane:ethyl acetate), and was used directly without further purification.

To a cooled $\left(0{ }^{\circ} \mathrm{C}\right)$ solution of the alcohol $(9.5 \mathrm{~g}$ crude mixture $)$ in DMF $(85 \mathrm{~mL})$ was added $\mathrm{NaH}$ (60\% dispersed in mineral oil, $1.6 \mathrm{~g})$. The mixture was stirred for $30 \mathrm{~min}$ and 4-methoxybenzyl chloride $(3.2 \mathrm{~mL})$ was added at $0{ }^{\circ} \mathrm{C}$. The mixture was then stirred for $2 \mathrm{~h}$ and quenched with saturated aqueous $\mathrm{NH}_{4} \mathrm{Cl}$. The mixture was diluted with $\mathrm{Et}_{2} \mathrm{O}(80$ $\mathrm{mL})$ and washed with water $(2 \times 40 \mathrm{~mL})$, then with brine. The organic layer was dried with $\mathrm{MgSO}_{4}$, filtered, and concentrated in vacuo. The residue was purified by column chromatography on silica gel (12:1 to $3: 1$ hexane:ethyl acetate) to provide $3.9 \mathrm{~g}$ of $\mathbf{8}$ (41\% over 2 steps) as a colorless oil; $[\alpha]_{\mathbf{D}}+34.5\left(c 1.64, \mathrm{CHCl}_{3}\right) ;{ }^{1} \mathbf{H}$ NMR (300 MHz, $\left.\mathbf{C D C l}_{3}\right): \delta 7.28(\mathrm{~m}, 2 \mathrm{H}), 6.89(\mathrm{~m}, 2 \mathrm{H}), 5.85(\mathrm{ddd}, J=7.4,10.0,17.6 \mathrm{~Hz}, 1 \mathrm{H}), 5.00-5.10$ $(\mathrm{m}, 2 \mathrm{H}), 4.65(\underline{\mathrm{ABq}}, J=10.9 \mathrm{~Hz}, 1 \mathrm{H}), 4.55(\mathrm{~A} \underline{\mathrm{B}} \mathrm{q}, J=10.9 \mathrm{~Hz}, 1 \mathrm{H}), 4.16(\mathrm{ddd}, J=4.9$, 6.3, $7.2 \mathrm{~Hz}, 1 \mathrm{H}), 3.98$ (dd, $J=6.3,8.1 \mathrm{~Hz}, 1 \mathrm{H}), 3.89$ (dd, $J=7.3,7.9 \mathrm{~Hz}, 1 \mathrm{H}), 3.80$ (s, $3 \mathrm{H}), 3.51(\mathrm{dd}, J=5.2,5.5 \mathrm{~Hz}, 1 \mathrm{H}), 2.37(\mathrm{~m}, 1 \mathrm{H}), 1.43(\mathrm{~s}, 3 \mathrm{H}), 1.35(\mathrm{~s}, 3 \mathrm{H}), 1.07$ (d, $J=$ $6.8 \mathrm{~Hz}, 3 \mathrm{H}) ;{ }^{13} \mathbf{C}$ NMR (300 MHz, $\left.\mathbf{C D C l}_{3}\right): \delta 159.29,141.35,130.92,129.58 \times 2$, $114.73,113.86 \times 2,108.78,82.23,77.05,74.31,65.77,55.41,40.55,26.77,25.61,15.49$; HRMS: calcd for $\mathrm{C}_{18} \mathrm{H}_{26} \mathrm{O}_{4}\left[\mathrm{MNa}^{+}\right] \mathrm{m} / z$ 329.1729, found 329.1726 . 


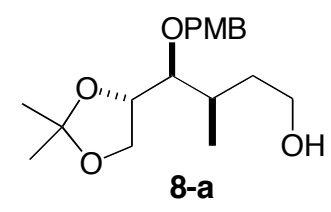

To a cooled $\left(0^{\circ} \mathrm{C}\right)$ solution of $8(580 \mathrm{mg}, 1.9 \mathrm{mmol})$ in THF $(20 \mathrm{~mL})$ under $\mathrm{N}_{2}$ atmosphere, was added a solution of 9-BBN in THF $(0.5 \mathrm{M}, 6.78 \mathrm{~mL}, 3.39 \mathrm{mmol})$ dropwise via syringe over $30 \mathrm{~min}$. The reaction was gradually allowed to warm to room temperature overnight. The resulting mixture was cooled back to $0{ }^{\circ} \mathrm{C}$, and aqueous $3 \mathrm{M}$ $\mathrm{NaOH}(8.5 \mathrm{~mL})$ and $30 \% \mathrm{H}_{2} \mathrm{O}_{2}(1.13 \mathrm{~mL})$ was added. This mixture was allowed to warm to room temperature and stirred for $3 \mathrm{~h}$, after which the volatiles were removed in vacuo. The residue was diluted with ethyl acetate and washed with water and brine. The organic layer was dried over $\mathrm{MgSO}_{4}$, filtered, concentrated, and purified by column chromatography (5:1 hexane:ethyl acetate to $100 \%$ ethyl acetate) to afford $1.778 \mathrm{~g}$ of $\mathbf{8 - a}$ $(98 \%)$ as a viscous oil; $[\alpha]_{\mathbf{D}}+24.4\left(c 1.64, \mathrm{CHCl}_{3}\right) ;{ }^{1} \mathbf{H}$ NMR (300 $\left.\mathbf{~ M H z}, \mathbf{C D C l}_{3}\right): \delta 7.25$ $(\mathrm{m}, 2 \mathrm{H}), 6.88(\mathrm{~m}, 2 \mathrm{H}), 4.60(\underline{\mathrm{ABq}}, J=10.9 \mathrm{~Hz}, 1 \mathrm{H}), 4.55(\mathrm{~A} \underline{\mathrm{Bq}}, J=10.9 \mathrm{~Hz}, 1 \mathrm{H}), 4.17$ (dd, $J=6.2,12.7 \mathrm{~Hz}, 1 \mathrm{H}), 4.04$ (dd, $J=6.2,8.2 \mathrm{~Hz}, 1 \mathrm{H}), 3.89$ (dd, $J=6.9,8.2 \mathrm{~Hz}, 1 \mathrm{H})$, $3.80(\mathrm{~s}, 3 \mathrm{H}), 3.56-3.75(\mathrm{~m}, 2 \mathrm{H}), 3.50(\mathrm{dd}, J=3.2,5.9 \mathrm{~Hz}, 1 \mathrm{H}), 1.97(\mathrm{~m}, 1 \mathrm{H}), 1.76(\mathrm{~m}$, 1H), 1.74 (br s, 1H), $1.53(\mathrm{~m}, 1 \mathrm{H}), 1.42(\mathrm{~s}, 3 \mathrm{H}), 1.35(\mathrm{~s}, 3 \mathrm{H}), 0.97$ (d, J=6.9 Hz, 3H); ${ }^{13}$ C NMR (300 MHz, $\left.\mathbf{C D C l}_{3}\right): \delta 159.35,130.60,129.52 \times 2,113.91 \times 2,108.67,82.72$, 76.83, 73.76, 66.91, 61.37, 55.40, 36.70, 32.66, 26.79, 25.39, 15.39; IR (neat) 3446, 2936, 1613, $1514 \mathrm{~cm}^{-1}$; HRMS : calcd for $\mathrm{C}_{18} \mathrm{H}_{28} \mathrm{O}_{5}\left[\mathrm{MNa}^{+}\right] \mathrm{m} / z$ 347.1834, found 347.1823.

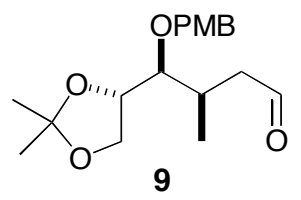

To a cooled $\left(-78^{\circ} \mathrm{C}\right)$, stirring solution of oxalyl choride $(1.35 \mathrm{~mL}, 15.2 \mathrm{mmol})$ in $\mathrm{CH}_{2} \mathrm{Cl}_{2}(32 \mathrm{~mL})$ under $\mathrm{N}_{2}$ atmosphere, was added DMSO $(2.4 \mathrm{~mL}, 34.9 \mathrm{mmol})$ as a solution in $\mathrm{CH}_{2} \mathrm{Cl}_{2}(6.5 \mathrm{~mL})$, and stirred for $20 \mathrm{~min}$. A solution of alcohol 8-a (4.32 $\mathrm{g}$, $13.3 \mathrm{mmol})$ in $\mathrm{CH}_{2} \mathrm{Cl}_{2}(15.5 \mathrm{~mL})$ was then added drop-wise and stirred for $30 \mathrm{~min}$, at which point $\mathrm{Et}_{3} \mathrm{~N}(9.25 \mathrm{~mL}, 66.4 \mathrm{mmol})$ was added and warmed gradually to room temperature. The mixture was stirred for approximately $1 \mathrm{~h}$ then diluted with $\mathrm{CH}_{2} \mathrm{Cl}_{2}$ and 
washed with water and brine. The solution was dried over $\mathrm{MgSO}_{4}$, filtered, and solvent removed in vacuo. The resulting residue was purified by silica gel chromatography $(8: 1$ to $3: 1$ hexane:ethyl acetate) to yield $4.0 \mathrm{~g}$ of $9(93 \%)$ as a yellowish oil; $[\boldsymbol{\alpha}]_{\mathbf{D}}+10.8$ (c 1.64, $\left.\mathrm{CHCl}_{3}\right) ;{ }^{1} \mathbf{H}$ NMR (300 MHz, $\left.\mathbf{C D C l}_{3}\right): \delta 9.71(\mathrm{t}, J=1.7 \mathrm{~Hz}, 1 \mathrm{H}), 7.23(\mathrm{~m}, 2 \mathrm{H})$, $6.88(\mathrm{~m}, 2 \mathrm{H}), 4.55(\underline{\mathrm{ABq}}, J=11.2 \mathrm{~Hz}, 1 \mathrm{H}), 4.48$ (Aㅁq, $J=11.2 \mathrm{~Hz}, 1 \mathrm{H}), 4.12-4.13$ (m, 2H), $3.86(\mathrm{dd}, J=6.0,7.8 \mathrm{~Hz}, 1 \mathrm{H}), 3.80(\mathrm{~s}, 3 \mathrm{H}), 3.48(\mathrm{dd}, J=3.0,6.1 \mathrm{~Hz}, 1 \mathrm{H}), 2.43-2.60$ (m, 2H), 2.35 (ddd, 2.2, 6.9, $15.3 \mathrm{~Hz}, 1 \mathrm{H}), 1.42$ (s, 3H), 1.34 (s, 3H), 1.00 (d, J=6.6 Hz, 3H); ${ }^{13}$ C NMR (300 MHz, $\left.\mathbf{C D C l}_{3}\right): \delta 202.23,159.42,130.39,129.58$ (× 2), $113.94(\times 2)$, $108.85,81.188,76.70,73.58,67.07,55.40,47.90,30.48,26.79,25.38,15.21$; IR (neat) 2985, 2719, 1723, 1612, $1514 \mathrm{~cm}^{-1}$; HRMS: calcd for $\mathrm{C}_{18} \mathrm{H}_{26} \mathrm{O}_{5}\left[\mathrm{MNa}^{+}\right] \mathrm{m} / z$ 345.1678, found 345.1661 .

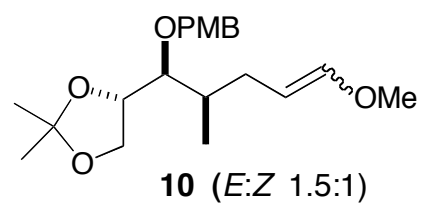

To a suspension of (methoxymethyl)triphenylphosphonium chloride (34.2 g, 99.8 $\mathrm{mmol})$ in THF $(150 \mathrm{~mL})$ under $\mathrm{N}_{2}$ at $-78{ }^{\circ} \mathrm{C}$, was added NaHMDS $(96.8 \mathrm{~mL}, 1 \mathrm{M}$ in THF) drop-wise and stirred at that temperature for $1 \mathrm{~h}$. A solution of aldehyde 9 (4.8 $\mathrm{g}$, $14.9 \mathrm{mmol})$ in THF $(51 \mathrm{~mL})$ was then slowly added via syringe and stirred for an additional $2 \mathrm{~h}$ at $-78^{\circ} \mathrm{C}$. The mixture was then warmed to room temperature and stirred for 30-45 min. until complete. The reaction was then quenched with a saturated aqueous $\mathrm{NaHCO}_{3}$ solution, extracted into $\mathrm{Et}_{2} \mathrm{O}$ and washed with brine. The organic layer was then dried over $\mathrm{MgSO}_{4}$, filtered, concentrated in vacuo, and purified by silica gel column chromatography (12:1 to 7:1 hexane:ethyl acetate) to afford $4.2 \mathrm{~g}(80 \%)$ of the methyl enol ether $\mathbf{1 0}$ as a colorless oil (ca. 1.5:1 E:Z); ${ }^{\mathbf{1}} \mathbf{H} \mathbf{N M R}\left(\mathbf{3 0 0} \mathbf{M H z}, \mathbf{C D C l}_{3}\right)$ : $\mathbf{m i x t u r e}$ of $\boldsymbol{E}: \boldsymbol{Z}$ isomers (ca. 1.5:1) $\delta$ 7.24-7.29 (m, 4H), 6.85-6.90 (m, 4H), $6.26(\mathrm{~d}, J=12.6 \mathrm{~Hz}$, $1 \mathrm{H}, E$-isomer), 5.94 (dt, $J=5.2,1.3 \mathrm{~Hz}, 1 \mathrm{H}, Z$-isomer), $4.51-4.71(\mathrm{~m}, 5 \mathrm{H}), 4.34$ (q, $J=$ $7.0 \mathrm{~Hz}, 1 \mathrm{H}$ ), 4.11-4.19 (overlapping q, $J=6.3 \mathrm{~Hz}, 1 \mathrm{H} \times 2$ ), 3.99-4.05 (m, 2H), 3.86-3.93 $(\mathrm{m}, 2 \mathrm{H}), 3.80(\mathrm{~s}, 6 \mathrm{H}), 3.57(\mathrm{~s}, 3 \mathrm{H}), 3.54-3.56(\mathrm{~m}, 2 \mathrm{H}), 3.50(\mathrm{~s}, 3 \mathrm{H}), 2.29(\mathrm{~m}, 1 \mathrm{H}), 1.96-$ $2.15(\mathrm{~m}, 2 \mathrm{H}), 1.86(\mathrm{~m}, 1 \mathrm{H}), 1.69-1.79(\mathrm{~m}, 2 \mathrm{H}), 1.43(\mathrm{~s}, 6 \mathrm{H}), 1.35(\mathrm{~s}, 6 \mathrm{H}), 0.94$ (d, J=6.0 $\mathrm{Hz}, 3 \mathrm{H}), 0.92(\mathrm{~d}, J=6.0 \mathrm{~Hz}, 3 \mathrm{H}) ;{ }^{13} \mathbf{C}$ NMR (300 MHz, $\left.\mathbf{C D C l}_{3}\right): \delta 159.25,159.20$, 
$148.23,147.09,131.30,131.07,129.44,129.35,113.86,113.82,108.56,108.55,105.07$, $101.27,81.60,81.42,77.42,77.29,74.31,73.98,66.62,66.55,59.59,56.03,55.39,36.82$, $35.99,32.37,28.50,26.84,25.52,25.43,14.80,14.40$; HRMS: calcd for $\mathrm{C}_{20} \mathrm{H}_{30} \mathrm{O}_{5}$ $\left[\mathrm{MNa}^{+}\right] \mathrm{m} / \mathrm{z} 373.1991$, found 373.1994.

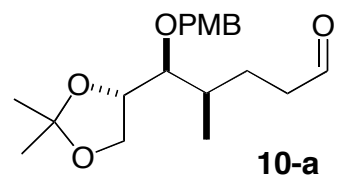

To a cooled $\left(-20^{\circ} \mathrm{C}\right)$ solution of $\mathrm{N}$-bromosuccinamide $(490 \mathrm{mg}, 2.75 \mathrm{mmol})$ in THF: $\mathrm{H}_{2} \mathrm{O}(25 \mathrm{~mL}: 4.3 \mathrm{~mL})$, was added a solution of the methyl enol ether $\mathbf{1 0}$ in THF (3 $\mathrm{mL}$ ) and stirred for 30-45 min. The volatiles were removed from the mixture in vacuo and the residue was diluted in ethyl acetate, and organic layer was separated and washed with brine. After drying over $\mathrm{MgSO}_{4}$, filtered, and concentrated in vacuo, the crude material was used directly in the next reaction without purification.

The crude $\alpha$-bromoaldehyde was dissolved in wet THF ( $9.6 \mathrm{~mL}$ ), glacial acetic acid (324 mg, $5.5 \mathrm{mmol}$ ) was added, and the solution cooled to $0{ }^{\circ} \mathrm{C}$. To a vigorously stirring solution was then added $\mathrm{Zn}$ dust ( $350 \mathrm{mg}, 5.5 \mathrm{mmol}$ ) portion-wise, and the mixture was allowed to gradually warm to room temperature. After stirring for $2 \mathrm{~h}$, the reaction was diluted in $\mathrm{Et}_{2} \mathrm{O}$ and washed with $\mathrm{H}_{2} \mathrm{O}$, saturated $\mathrm{NaHCO}_{3}$, and brine. The organic layer was dried over $\mathrm{MgSO}_{4}$, filtered, and concentrated in vacuo. The residue was purified by silica gel column chromatography (5:1 to $1: 1$ hexane:ethyl acetate) to yield $790 \mathrm{mg}(87 \%$ over 2 steps) of aldehyde 10-a as a colorless oil; ${ }^{1} \mathbf{H}$ NMR (300 $\left.\mathbf{M H z}, \mathbf{C D C l}_{3}\right): \delta 9.74$ (t, $J=1.5 \mathrm{~Hz}, 1 \mathrm{H}), 7.25(\mathrm{~m}, 2 \mathrm{H}), 6.87(\mathrm{~m}, 2 \mathrm{H}), 4.60(\underline{\mathrm{ABq}}, J=10.9,1 \mathrm{H}), 4.53$ (Aㅁq, $J=$ $10.9,1 \mathrm{H}), 4.13(\mathrm{dd}, J=6.2,12.5 \mathrm{~Hz}, 1 \mathrm{H}), 4.05(\mathrm{dd}, J=6.2,7.9 \mathrm{~Hz}, 1 \mathrm{H}) 3.90(\mathrm{dd}, J=$ 6.6, 7.9 Hz, 1H), 3.80 (s, 3H), $3.47(\mathrm{dd}, J=3.0,6.0 \mathrm{~Hz}, 1 \mathrm{H}), 2.32-2.55(\mathrm{~m}, 2 \mathrm{H}), 1.72-$ $1.88(\mathrm{~m}, 2 \mathrm{H}), 1.56(\mathrm{~m}, 1 \mathrm{H}), 1.42(\mathrm{~s}, 3 \mathrm{H}), 1.35(\mathrm{~s}, 3 \mathrm{H}), 0.94(\mathrm{~d}, J=7.0 \mathrm{~Hz}, 3 \mathrm{H}) ;{ }^{13} \mathrm{C}$ NMR (300 MHz, $\left.\mathbf{C D C l}_{3}\right): \delta 202.51,159.36,130.70,129.52 \times 2,113.91 \times 2,108.69$, 82.20, 76.94, 73.87, 66.87, 55.41, 42.16, 35.09, 26.83, 26.00, 25.38, 14.50; HRMS: calcd for $\mathrm{C}_{19} \mathrm{H}_{28} \mathrm{O}_{5}\left[\mathrm{MNa}^{+}\right] \mathrm{m} / \mathrm{z} 391.2097$, found 391.2109. 


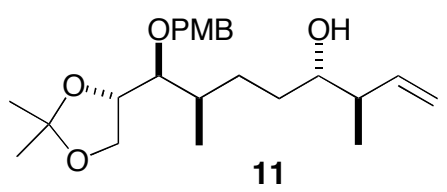

To a stirred mixture of potassium tert-butoxide $1.35 \mathrm{~g}, 12.0 \mathrm{mmol})$, THF $(2.0 \mathrm{~mL})$, and trans-2-butene (2.2 $\mathrm{mL}, 4.1 \mathrm{mmol}), n$-butyllithium in hexanes $(2.5 \mathrm{M}, 12.0 \mathrm{mmol})$ was added slowly at $-78{ }^{\circ} \mathrm{C}$ under $\mathrm{N}_{2}$ atmosphere. After complete addition of $n$ butyllithium, the mixture was stirred at $-45^{\circ} \mathrm{C}$ for $10 \mathrm{~min}$. The resulting solution was cooled back to $-78{ }^{\circ} \mathrm{C}$, and to it was added drop-wise (+)-B-methoxydiisopinocampheylborane in ether $(1 \mathrm{M}, 14.5 \mathrm{mmol})$. After the reaction mixture was stirred at $-78{ }^{\circ} \mathrm{C}$ for $30 \mathrm{~min}, \mathrm{BF}_{3} \cdot \mathrm{OEt}_{2}(2.0 \mathrm{~mL}, 16.1 \mathrm{mmol})$ was added drop-wise. Then aldehyde 10-a (9.5 g, $73.0 \mathrm{mmol})$ was added drop-wise as a solution in $\mathrm{Et}_{2} \mathrm{O}$ at $-78{ }^{\circ} \mathrm{C}$. The mixture was stirred at this temperature for $4 \mathrm{~h}$ then treated with $4.2 \mathrm{~mL}$ of $3 \mathrm{M} \mathrm{NaOH}$ and $1.7 \mathrm{~mL} 30 \% \mathrm{H}_{2} \mathrm{O}_{2}$, and the contents were refluxed for $1 \mathrm{~h}$. The organic layer was separated and washed with water and brine, dried over $\mathrm{MgSO}_{4}$, filtered, and concentrated in vacuo. The residue was purified by silica gel column chromatography (9:1 to 3:1 hexane:ethyl acetate) to afford $1.8 \mathrm{~g}(57 \%)$ of crotylation product 11 as a colorless oil; ${ }^{1} \mathbf{H}$ NMR (300 MHz, CDCl $)$ ): $\delta 7.25$ (m, 2H), 6.87 (m, 2H), 5.74 (ddd, $J=10.9,16.6,8.2$ $\mathrm{Hz}, 1 \mathrm{H}), 5.13$ (s, 1H), $5.08(\mathrm{~m}, 1 \mathrm{H}), 4.62(\underline{\mathrm{ABq}}, J=11.0 \mathrm{~Hz}, 1 \mathrm{H}), 4.54$ (Aq, $J=11.0$ Hz, 1H), 4.15 (m, 1H), 4.03 (dd, $J=6.3,8.1 \mathrm{~Hz}, 1 \mathrm{H}), 3.90$ (dd, $J=7.0,7.9 \mathrm{~Hz}, 1 \mathrm{H}), 3.79$ (s, 3H), 3.50 (dd, $J=3.6,5.6 \mathrm{~Hz}, 1 \mathrm{H}), 3.35(\mathrm{~m}, 1 \mathrm{H}), 2.18(\mathrm{~m}, 1 \mathrm{H}), 1.73(\mathrm{~m}, 1 \mathrm{H}), 1.39$ 1.51 (m, 4H), 1.43 (s, 3H), 1.35 (s, 3H), 1.02 (dd, $J=6.9 \mathrm{~Hz}, 3 \mathrm{H}), 0.93$ (dd, $J=6.9 \mathrm{~Hz}$, 3H); ${ }^{13} \mathbf{C}$ NMR (300 MHz, $\mathbf{C D C l}_{3}$ ): (major diastereomer) $\delta$ 159.22, 140.37, 131.00, $129.43,116.43,113.81,108.54,82.46,77.16,74.68,74.02,66.60,55.34,44.29,35.59$, $32.10,29.87,26.80,25.43,16.40,14.75$; (distinguishable signals from minor diastereomer) $\delta 82.32,77.09,72.26,71.99,66.73,37.27,27.92,22.82,14.21$; HRMS: calcd for $\mathrm{C}_{23} \mathrm{H}_{36} \mathrm{O}_{5}\left[\mathrm{MNa}^{+}\right] \mathrm{m} / z$ 415.2460, found 415.2451.

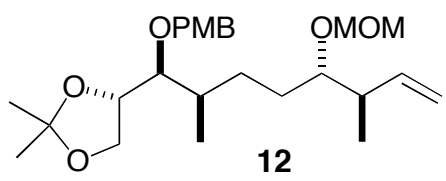


To a cooled $\left(0{ }^{\circ} \mathrm{C}\right)$ solution of $\mathbf{1 1}$ in $\mathrm{CH}_{2} \mathrm{Cl}_{2}(8.0 \mathrm{~mL})$ was added DIEA (diisopropylethylamine, 395mg, $3.1 \mathrm{mmol}$ ) drop-wise followed by MOM-Cl (chloromethyl methyl ether, $246 \mathrm{mg}, 3.1 \mathrm{mmol})$. The solution was gradually warmed to room temperature until reaction was determined to be complete by TLC, at which point it was quenched with saturated $\mathrm{NH}_{4} \mathrm{Cl}$ and diluted with $\mathrm{CH}_{2} \mathrm{Cl}_{2}$. The organic layer was washed with saturated $\mathrm{NH}_{4} \mathrm{Cl}, \mathrm{H}_{2} \mathrm{O}$, then brine, and dried over $\mathrm{MgSO}_{4}$. The solution was filtered, concentrated in vacuo and purified by silica gel column chromatography (9:1 to 5:1 hexane:ethyl acetate) to afford $333 \mathrm{mg}(75 \%)$ of 12 as a colorless oil; ${ }^{1} \mathbf{H}$ NMR (300 MHz, $\left.\mathbf{C D C l}_{3}\right)$ : $\delta$ $7.24(\mathrm{~m}, 2 \mathrm{H}), 6.87(\mathrm{~m}, 2 \mathrm{H}), 5.78(\mathrm{~m}, 1 \mathrm{H}), 5.03(\mathrm{~m}, 2 \mathrm{H}), 4.67$ (스, $J=6.8 \mathrm{~Hz}, 1 \mathrm{H}), 4.63$ $(\mathrm{A} \underline{\mathrm{Bq}}, J=6.8 \mathrm{~Hz}, 1 \mathrm{H}), 4.60(\underline{\mathrm{ABq}}, J=11.2 \mathrm{~Hz}, 1 \mathrm{H}), 4.52(\mathrm{~A} \underline{\mathrm{Bq}}, J=11.2 \mathrm{~Hz}, 1 \mathrm{H}), 4.13$ $(\mathrm{m}, 1 \mathrm{H}), 4.02(\mathrm{dd}, J=6.3,8.1 \mathrm{~Hz}, 1 \mathrm{H}), 3.90(\mathrm{dd}, J=6.8,8.0 \mathrm{~Hz}, 1 \mathrm{H}), 3.80(\mathrm{~s}, 3 \mathrm{H}), 3.48$ $(\mathrm{dd}, J=3.4,5.5 \mathrm{~Hz}, 1 \mathrm{H}), 3.42(\mathrm{~m}, 1 \mathrm{H}), 3.38(\mathrm{~s}, 3 \mathrm{H}), 2.44(\mathrm{~m}, 1 \mathrm{H}), 1.72(\mathrm{~m}, 1 \mathrm{H}), 1.32-$ $1.59(\mathrm{~m}, 4 \mathrm{H}), 1.42(\mathrm{~s}, 3 \mathrm{H}), 1.35(\mathrm{~s}, 3 \mathrm{H}), 1.03(\mathrm{~d}, J=7.1 \mathrm{~Hz}, 3 \mathrm{H}), 0.92$ (d, J=7.0 Hz, 3H); ${ }^{13}$ C NMR (300 MHz, $\mathbf{C D C l}_{3}$ ): (major diastereomer) $\delta$ 159.28, 140.71, 131.08, $129.32 \times 2,114.89,113.85 \times 2,108.56,96.32,82.66,81.80,77.16,74.06,66.70,55.81$, 55.37, 41.07, 35.80, 30.03, 29.16, 26.82, 25.44, 15.09, 14.71; (distinguishable signals from minor diastereomer): $\delta$ 95.57, 82.61, 77.79, 55.62, 34.11, 32.39, 29.56, 27.61, 22.99, 14.79, 14.21; HRMS: calcd for $\mathrm{C}_{25} \mathrm{H}_{40} \mathrm{O}_{6}\left[\mathrm{MNa}^{+}\right] m / z$ 459.2723, found 459.2712.

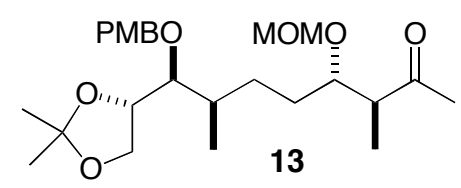

To a solution of the alkene $12(197 \mathrm{mg}, 0.45 \mathrm{mmol})$ in DMF $(4.0 \mathrm{~mL})$, THF $(0.6 \mathrm{~mL})$, and water $(0.6 \mathrm{~mL})$ was added $\mathrm{CuCl}(62 \mathrm{mg}, 0.60 \mathrm{mmol})$ and $\mathrm{PdCl}_{2}(20 \mathrm{mg}, 0.11 \mathrm{mmol})$. The solution was flushed with oxygen for 15-20 min. and then stirred under an atmosphere of oxygen for 2.5 days at room temperature. The reaction mixture was diluted with ethyl acetate and poured into water. The aqueous layer was extracted with ethyl acetate. The combined organic layers were washed with saturated aqueous $\mathrm{NH}_{4} \mathrm{Cl}$, saturated aqueous $\mathrm{NaHCO}_{3}$, brine, and the dried over $\mathrm{MgSO}_{4}$, filtered, and concentrated in vacuo. The residue was purified by silica gel column chromatography (6:1 to $2: 1$ hexane:ethyl acetate) to afford $144 \mathrm{mg}(71 \%)$ ketone 13 as a colorless oil along with a 
trace amount of an inseparable regioisomeric side product aldehyde. ${ }^{1} \mathbf{H}$ NMR (300 MHz, $\left.\mathbf{C D C l}_{3}\right): \delta 7.25$ (m, 2H), $6.87(\mathrm{~m}, 2 \mathrm{H}), 4.61(\underline{\mathrm{ABq}}, J=10.8 \mathrm{~Hz}, 1 \mathrm{H}), 4.53$ (Aㅁq, $J$ $=10.8 \mathrm{~Hz}, 1 \mathrm{H}), 4.59(\mathrm{~s}, 2 \mathrm{H}), 4.14(\mathrm{q}, J=6.3 \mathrm{~Hz}, 1 \mathrm{H}), 4.02(\mathrm{dd}, J=6.3,8.0 \mathrm{~Hz}, 1 \mathrm{H}), 3.89$ (dd, $J=6.8,8.0 \mathrm{~Hz}, 1 \mathrm{H}), 3.77-3.85(\mathrm{~m}, 1 \mathrm{H}), 3.80(\mathrm{~s}, 3 \mathrm{H}), 3.47(\mathrm{dd}, J=3.4,5.7 \mathrm{~Hz}, 1 \mathrm{H})$, 3.32 (s, 3H), 2.83 (quintet, $J=7.1 \mathrm{~Hz}, 1 \mathrm{H}), 2.18(\mathrm{~s}, 3 \mathrm{H}), 1.72(\mathrm{~m}, 1 \mathrm{H}), 1.24-1.58(\mathrm{~m}$, 4H), $1.42(\mathrm{~s}, 3 \mathrm{H}), 1.35$ (s, 3H), $1.03(\mathrm{~d}, J=7.0 \mathrm{~Hz}, 3 \mathrm{H}), 0.92(\mathrm{~d}, J=6.9 \mathrm{~Hz}, 3 \mathrm{H}) ;{ }^{13} \mathbf{C}$ NMR (300 MHz, $\left.\mathbf{C D C l}_{3}\right): \delta 211.36,159.22,130.95,129.33 \times 2,113.81 \times 2,108.57$, $96.31,82.88,79.09,76.97,74.03,66.69,55.92,55.34,50.20,35.74,29.96,28.90,28.47$, 26.79, 25.43, 14.51, 12.15; (trace amount of aldehyde side product from Wacker oxidation): 202.34, 82.71, 81.91, 77.03, 47.57, 31.48, 16.49, 14.57; HRMS: calcd for $\mathrm{C}_{25} \mathrm{H}_{40} \mathrm{O}_{7}\left[\mathrm{MNa}^{+}\right] \mathrm{m} / z$ 475.2672, found 475.2666.

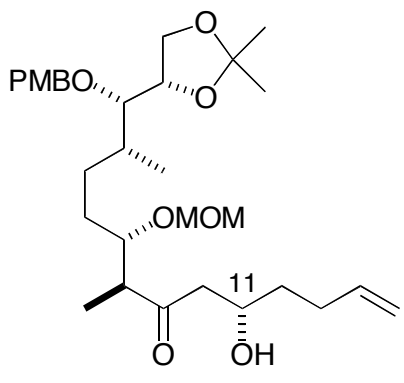

18 (and 11-epimer, 86:14)

To a cooled $\left(0^{\circ} \mathrm{C}\right)$ solution of (-)-B-chlorodiisopinocampheylborane (194 mg, 0.60 mmol $)$ in $\mathrm{Et}_{2} \mathrm{O}(2 \mathrm{~mL})$ was added $\mathrm{Et}_{3} \mathrm{~N}(0.13 \mathrm{~mL}, 0.93 \mathrm{mmol})$ under $\mathrm{N}_{2}$ atmosphere. A solution of ketone $13(100 \mathrm{mg}, 0.22 \mathrm{mmol})$ in $\mathrm{Et}_{2} \mathrm{O}(2 \mathrm{~mL})$ was added via syringe and the reaction was maintained at $0{ }^{\circ} \mathrm{C}$ for $90-100 \mathrm{~min}$. The reaction mixture was then cooled to $-78^{\circ} \mathrm{C}$ and a solution of 5-hexenal in $\mathrm{Et}_{2} \mathrm{O}(1.5 \mathrm{~mL})$ was added via syringe. The reaction mixture was maintained at $-78{ }^{\circ} \mathrm{C}$ for $3.5 \mathrm{~h}$ and then warmed to $-20{ }^{\circ} \mathrm{C}$ and maintained at that temperature overnight. The reaction mixture was quenched by sequential addition of $\mathrm{MeOH}(1.7 \mathrm{~mL})$, $\mathrm{pH} 7$ buffer $(0.6 \mathrm{~mL})$, and $30 \% \mathrm{H}_{2} \mathrm{O}_{2}(0.6 \mathrm{~mL})$. The resulting mixture was then diluted with $\mathrm{CH}_{2} \mathrm{Cl}_{2}$ and poured into water. The aqueous layer was extracted with $\mathrm{CH}_{2} \mathrm{Cl}_{2}$, and the combined organic layers were washed with brine, dried over $\mathrm{MgSO}_{4}$, filtered, and concentrated in vacuo. The residue was purified by silica gel column chromatography ( $8: 1$ to $1: 1$ hexanes:ethyl acetate) to afford $85 \mathrm{mg}$ of $\mathbf{1 8}$ (72\%, 
86:14 of 18 and it's C-11 epimer); ${ }^{1} \mathbf{H}$ NMR (300 $\left.\mathbf{M H z}, \mathbf{C D C l}_{3}\right)$ : (major diastereomer) $\delta$ $7.25(\mathrm{~m}, 2 \mathrm{H}), 6.87(\mathrm{~m}, 2 \mathrm{H}), 5.82$ (ddt, $J=6.6,10.3,17.0 \mathrm{~Hz}, 1 \mathrm{H}), 4.95-5.08(\mathrm{~m}, 2 \mathrm{H})$, $4.61(\underline{\mathrm{ABq}}, J=10.8 \mathrm{~Hz}, 1 \mathrm{H}), 4.52(\mathrm{AB} q, J=10.8 \mathrm{~Hz}, 1 \mathrm{H}), 4.53-4.62(\mathrm{~m}, 2 \mathrm{H}), 4.14(\mathrm{q}, J=$ $6.3,1 \mathrm{H}), 4.05(\mathrm{~m}, 1 \mathrm{H}), 4.03(\mathrm{dd}, J=6.3,7.9 \mathrm{~Hz}, 1 \mathrm{H}), 3.89(\mathrm{dd}, J=7.1,7.9 \mathrm{~Hz}, 1 \mathrm{H}), 3.81$ (m, 1H), $3.80(\mathrm{~s}, 3 \mathrm{H}), 3.46(\mathrm{dd}, J=3.4,5.5 \mathrm{~Hz}, 1 \mathrm{H}), 3.30(\mathrm{~s}, 3 \mathrm{H}), 3.19(\mathrm{~d}, J=3.5 \mathrm{~Hz}$, 1H) $2.82(\mathrm{~m}, 1 \mathrm{H}), 2.53-2.72(\mathrm{~m}, 2 \mathrm{H}), 2.07-2.29(\mathrm{~m}, 2 \mathrm{H}), 1.71(\mathrm{~m}, 1 \mathrm{H}), 1.45-1.67(\mathrm{~m}$, 5H), $1.42(\mathrm{~s}, 3 \mathrm{H}), 1.35(\mathrm{~s}, 3 \mathrm{H}), 1.25(\mathrm{~m}, 1 \mathrm{H}), 1.01(\mathrm{~d}, J=7.1 \mathrm{~Hz}, 3 \mathrm{H}), 0.93(\mathrm{~d}, J=6.8$ $\mathrm{Hz}, 3 \mathrm{H}) ;{ }^{13} \mathbf{C}$ NMR (300 MHz, $\mathbf{C D C l}_{3}$ ): (major diastereomer) $\delta 214.60,159.26,138.27$, $130.95,129.27,114.94,113.84,108.59,96.28,82.94,79.27,76.98,73.97,66.96,66.73$, $55.97,55.33$, 49.78, 49.75, 35.78, 35.58, 29.82, 28.86, 28.08, 26.78, 25.42, 14.52, 12.45;

HRMS: calcd for $\mathrm{C}_{30} \mathrm{H}_{48} \mathrm{O}_{8}\left[\mathrm{MNa}^{+}\right] \mathrm{m} / z$ 559.3247, found 559.3263

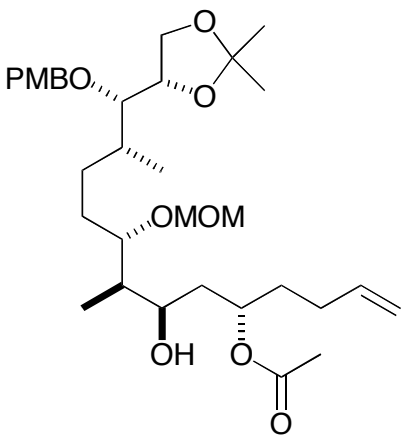

19

To a cooled $\left(-10{ }^{\circ} \mathrm{C}\right)$ solution of $18(446 \mathrm{mg}, 0.83 \mathrm{mmol})$ in THF $(2.8 \mathrm{~mL})$ under $\mathrm{N}_{2}$ atmosphere, was added acetaldehyde $(0.22 \mathrm{~mL}, 4.16 \mathrm{mmol})$. To this solution was added $\mathrm{SmI}_{2}(0.83 \mathrm{mmol}, 0.1 \mathrm{M}$ in THF) slowly in the dark. After stirring for $1.5 \mathrm{~h}$ in the dark at $-10{ }^{\circ} \mathrm{C}$, the reaction was diluted with ethyl acetate, washed with saturated $\mathrm{NaHCO}_{3}$, brine, dried over $\mathrm{MgSO}_{4}$. The solution was filtered, concentrated in vacuo, and the residue purified by silica gel column chromatography $(2: 1$ hexanes:ethyl acetate) to afford $480 \mathrm{mg}$ (99\%) of product 19 as an oil; ${ }^{1} \mathbf{H}$ NMR (300 MHz, $\mathbf{C D C l}_{3}$ ): (major diastereomer) $\delta 7.26(\mathrm{~m}, 2 \mathrm{H}), 6.87(\mathrm{~m}, 2 \mathrm{H}), 5.79(\mathrm{~m}, 1 \mathrm{H}), 5.11(\mathrm{~m}, 1 \mathrm{H}), 4.94-5.05(\mathrm{~m}$, 2H), 4.53-4.66 (m, 4H), $4.16(\mathrm{q}, J=6.2 \mathrm{~Hz}, 1 \mathrm{H}), 4.03(\mathrm{dd}, J=6.2,8.0 \mathrm{~Hz}, 1 \mathrm{H}), 3.90$ (dd, $J=6.8,8.0 \mathrm{~Hz}, 1 \mathrm{H}), 3.81$ (s, 3H), 3.74 (br m, 1H), 3.47 (dd, $J=3.4,5.6 \mathrm{~Hz}, 1 \mathrm{H}), 3.36$ (s, $3 \mathrm{H}), 3.26(\mathrm{~d}, J=3.7 \mathrm{~Hz}, 1 \mathrm{H}), 2.08,(\mathrm{~s}, 3 \mathrm{H}), 2.06-2.15(\mathrm{~m}, 2 \mathrm{H}), 1.88(\mathrm{~m}, 1 \mathrm{H}), 1.44-1.78$ $(\mathrm{m}, 8 \mathrm{H}), 1.42$ (s, 3H), 1.35 (s, 3H), 0.93, (d, $J=6.9 \mathrm{~Hz}, 3 \mathrm{H}), 0.84(\mathrm{~d}, J=7.0 \mathrm{~Hz}, 3 \mathrm{H})$; 
${ }^{13}$ C NMR (300 MHz, $\mathbf{C D C l}_{3}$ ): (major diastereomer) $\delta$ 172.26, 159.25, 137.63, 131.08, $129.32,115.27,113.86,108.55,96.19,83.09,79.56,77.06,74.13,71.44,68.79,66.72$, 55.90, 55.37, 41.90, 40.02, 35.72, 34.37, 29.95, 29.59, 28.08, 26.80, 25.44, 21.19, 14.52, 11.16; HRMS: calcd for $\mathrm{C}_{32} \mathrm{H}_{52} \mathrm{O}_{9}\left[\mathrm{MNa}^{+}\right] \mathrm{m} / z$ 603.3509, found 603.3487 .

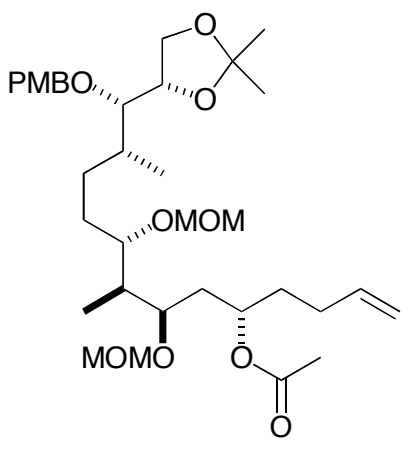

19-a

To a cooled $\left(0{ }^{\circ} \mathrm{C}\right)$ solution of $19(480 \mathrm{mg}, 0.83 \mathrm{mmol})$ in $\mathrm{CH}_{2} \mathrm{Cl}_{2}(9.0 \mathrm{~mL})$ was added DIEA ( $N, N$-diisopropylethylamine, $323 \mathrm{mg}, 2.5 \mathrm{mmol}$ ) drop-wise followed by $\mathrm{MOMCl}$ (chloromethyl methyl ether, $201 \mathrm{mg}, 2.5 \mathrm{mmol}$ ). The solution was gradually warmed to room temperature until reaction was determined to be complete by TLC, at which point it was quenched with saturated $\mathrm{NH}_{4} \mathrm{Cl}$ and diluted with $\mathrm{CH}_{2} \mathrm{Cl}_{2}$. The organic layer was washed with saturated $\mathrm{NH}_{4} \mathrm{Cl}, \mathrm{H}_{2} \mathrm{O}$, then brine, and dried over $\mathrm{MgSO}_{4}$. The solution was concentrated in vacuo and purified by silica gel column chromatography (5:1 to 2:1 hexane:ethyl acetate) to afford $390 \mathrm{mg}(76 \%)$ of 19-a as an oil; ${ }^{\mathbf{1}} \mathbf{H}$ NMR (300 MHz, $\mathbf{C D C l}_{3}$ ): (major diastereomer) $\delta 7.25(\mathrm{~m}, 2 \mathrm{H}), 6.86(\mathrm{~m}, 2 \mathrm{H}), 5.80(\mathrm{~m}, 1 \mathrm{H}), 5.08$ (m, 1H), $5.0(\mathrm{~m}, 2 \mathrm{H}), 4.52-4.65(\mathrm{~m}, 6 \mathrm{H}), 4.16(\mathrm{q}, J=6.5 \mathrm{~Hz}, 1 \mathrm{H}), 4.02$ (dd, $J=6.5,8.0$ $\mathrm{Hz}, 1 \mathrm{H}), 3.90$ (dd, $J=6.9,8.0 \mathrm{~Hz}, 1 \mathrm{H}), 3.79$ (s, 3H), 3.74 (m, 1H), 3.47 (dd, $J=3.8,5.5$ $\mathrm{Hz}, 1 \mathrm{H} \times 2), 3.42(\mathrm{~m}, 1 \mathrm{H}), 3.37(\mathrm{~s}, 3 \mathrm{H}), 3.34(\mathrm{~s}, 3 \mathrm{H}), 2.07$ (dd, $J=7.4,14.6 \mathrm{~Hz}, 2 \mathrm{H})$, $2.02(\mathrm{~s}, 3 \mathrm{H}), 1.60-1.79(\mathrm{~m}, 9 \mathrm{H}), 1.42(\mathrm{~s}, 3 \mathrm{H}), 1.35$ (s, 3H), 1.35 (m, 1H), 0.94 (d, $J=6.7$ $\mathrm{Hz}, 3 \mathrm{H}), 0,87$ (d , $J=7.0 \mathrm{~Hz}, 3 \mathrm{H}) ;{ }^{13} \mathbf{C}$ NMR (300 MHz, $\mathbf{C D C l}_{3}$ ): (major diastereomer) $\delta$ 170.67, 159.21, 137.94, 130.95, 129.29, 114.92, 113.79, 108.56, 96.81, 96.38, 83.06, $79.65,76.97,75.53,74.09,71.17,66.61,56.00,55.93,55.33,39.61,36.04,34.99,34.46$, 29.53, 29.47, 28.46, 26.78, 25.44, 21.32, 14.55, 10.35; HRMS: calcd for $\mathrm{C}_{34} \mathrm{H}_{56} \mathrm{O}_{10}$ $\left[\mathrm{MNa}^{+}\right] \mathrm{m} / \mathrm{z} 647.3771$, found 647.3781 . 


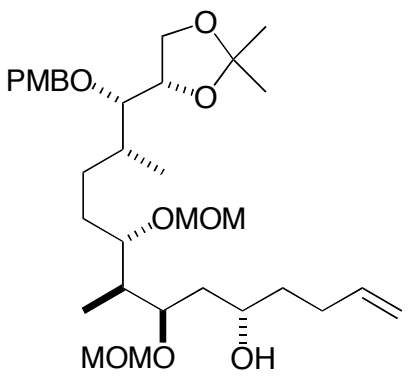

20

To a solution of 19-a (340 mg, $0.54 \mathrm{mmol})$ in methanol $(6.0 \mathrm{~mL})$ was added $\mathrm{K}_{2} \mathrm{CO}_{3}$ (298 mg, $2.16 \mathrm{mmol}$ ) and stirred vigorously at reflux for 2-3 h. The reaction mixture was diluted with ethyl acetate, quenched with $\mathrm{pH} 7$ buffer, and the organic layer was separated and washed with brine. The solution was dried over $\mathrm{MgSO}_{4}$, filtered, and concentrated in vacuo. The residue was purified by silica gel column chromatography (3:1 to 1:1 hexanes:ethyl acetate) to afford $291 \mathrm{mg}(92 \%)$ of 20 as an oil; ${ }^{1} \mathbf{H}$ NMR (300 MHz, $\left.\mathbf{C D C l}_{3}\right)$ : (major diastereomer) $\delta 7.26(\mathrm{~m}, 2 \mathrm{H}), 6.88(\mathrm{~m}, 2 \mathrm{H}), 5.86(\mathrm{~m}, 1 \mathrm{H}), 5.04$ $(\mathrm{m}, 1 \mathrm{H}), 4.96(\mathrm{~m}, 1 \mathrm{H}), 4.52-4.67$ (overlapping doublets, $6 \mathrm{H}), 4.15(\mathrm{q}, J=7.0 \mathrm{~Hz}, 1 \mathrm{H})$, $4.02(\mathrm{dd}, J=6.4,8.0 \mathrm{~Hz}, 1 \mathrm{H}), 3.90(\mathrm{dd}, J=7.0,8.0 \mathrm{~Hz}, 1 \mathrm{H}), 3.81-3.89$ (m, 2H), 3.80 (s, $3 \mathrm{H}), 3.48(\mathrm{~m}, 2 \mathrm{H}), 3.39$ (s, 3H), $3.38(\mathrm{~s}, 3 \mathrm{H}), 3.03$ (d, J=4.0 Hz, 1H), 2.08-2.30 (m, 2H), 2.02 (sextet, $J=7.0 \mathrm{~Hz}, 1 \mathrm{H}), 1.37-1.83(\mathrm{~m}, 9 \mathrm{H}), 1.42$ (s, 3H), 1.35 (s, 3H), 0.94 (d, $J=$ $6.9 \mathrm{~Hz}, 3 \mathrm{H}), 0.84(\mathrm{~d}, J=6.9 \mathrm{~Hz}, 3 \mathrm{H}) ;{ }^{13} \mathbf{C}$ NMR (300 MHz, CDCl $\mathbf{~}_{3}$ ): (major diastereomer) $\delta 159.22,138.80,130.97,129.29,114.67,113.82,108.57,96.72,96.38$, $82.91,79.56,77.03,76.63,74.02,67.33,66.65,56.19,56.01,55.35,39.92,37.61,36.94$, $35.98,30.26,29.13,28.93,26.80,25.44,14.68,10.53$; HRMS: calcd for $\mathrm{C}_{32} \mathrm{H}_{54} \mathrm{O}_{9}$ $\left[\mathrm{MNa}^{+}\right] m / z 605.3666$, found 605.3642 .

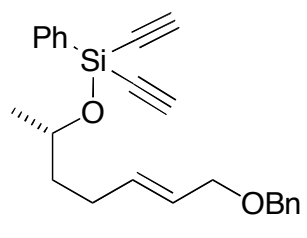

21

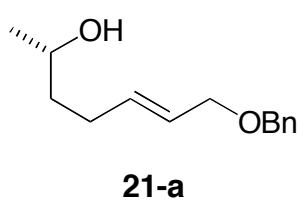

To a stirring solution of phenyltriethynylsilane $(136 \mathrm{mg}, 0.75 \mathrm{mmol})$ and alcohol 21-a $(83 \mathrm{mg}, 0.38 \mathrm{mmol})$ in dry hexanes $(1.6 \mathrm{~mL})$ was added $\mathrm{NaH}(60 \%$ dispersion in mineral oil, $1.5 \mathrm{mg}, 38 \mu \mathrm{mol}$ ) and stirred at room temperature for $1-2 \mathrm{~h}$. The reaction mixture 
was filtered through a pad of celite, concentrated in vacuo, and the residue purified by silica gel chromatography (10\% ether in hexanes) to afford silyl ether 21 (89 mg, $63 \%$ ); ${ }^{1}$ H NMR (300 MHz, $\left.\mathbf{C D C l}_{3}\right): \delta 7.79$ (m, 2H), 7.25-7.50 (m, 8H), $5.66(\mathrm{~m}, 2 \mathrm{H}), 4.49$ (s, 3H), 4.22 (sextet, $J=6.1 \mathrm{~Hz}, 1 \mathrm{H}), 3.95(\mathrm{~d}, J=5.8 \mathrm{~Hz}, 2 \mathrm{H}), 2.63$ (s, 1H), $2.62(\mathrm{~s}, 1 \mathrm{H})$, $2.16(\mathrm{~m}, 2 \mathrm{H}), 1.47-1.76(\mathrm{~m}, 2 \mathrm{H}), 1.28(\mathrm{~d}, J=6.0 \mathrm{~Hz}, 3 \mathrm{H}) ;{ }^{13} \mathbf{C}$ NMR (300 MHz, $\left.\mathbf{C D C l}_{3}\right)$ : ठ 138.57, 134.43, 134.26, 131.19, 128.49, 128.21, 127.92, 127.67, 126.62, 95.67, 95.59, 84.60, 84.49, 72.00, 71.03, 70.98, 38.29, 28.56, 23.23; HRMS: calcd for $\mathrm{C}_{24} \mathrm{H}_{26} \mathrm{O}_{2} \mathrm{Si}$ $\left[\mathrm{MNa}^{+}\right] \mathrm{m} / \mathrm{z} 397.1600$, found 397.1592 .

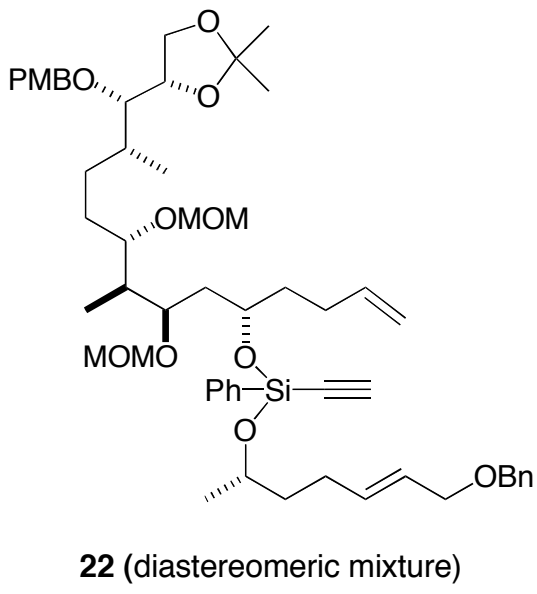

To a solution of secondary alcohol $20(140 \mathrm{mg}, 0.24 \mathrm{mmol})$ and silyl ether $21(89 \mathrm{mg}$, $0.24 \mathrm{mmol})$ in hexanes $(3.0 \mathrm{~mL})$ was added $\mathrm{NaH}(60 \%$ dispersion in mineral oil, $1.0 \mathrm{mg}$, $24.0 \mu \mathrm{mol}$ ) and stirred over gentle heating for $4-5 \mathrm{~h}$. The reaction mixture was filtered through a pad of celite, concentrated in vacuo, and the residue purified by silica gel chromatography (5:1 to 3:1 hexane:ethyl acetate) to afford $129 \mathrm{mg}(58 \%)$ of silaketal 22; ${ }^{1} \mathbf{H}$ NMR (300 MHz, $\mathbf{C D C l}_{3}$ ): (mixture of two diastereomers) $\delta 7.73(\mathrm{~m}, 2 \mathrm{H} \times 2)$, 7.23$7.43(\mathrm{~m}, 10 \mathrm{H} \times 2), 6.86(\mathrm{~d}, J=8.5 \mathrm{~Hz}, 2 \mathrm{H} \times 2), 5.46-5.89(\mathrm{~m}, 3 \mathrm{H} \times 2), 4.88-5.05(\mathrm{~m}, 2 \mathrm{H}$ $\times 2$ ), 4.42-4.70 (overlapping doublets, $8 \mathrm{H} \times 2), 4.27(\mathrm{~m}, 1 \mathrm{H} \times 2) 4.15(\mathrm{~m}, 2 \mathrm{H} \times 2), 3.85$ $4.04(\mathrm{~m}, 5 \mathrm{H} \times 2), 3.79(\mathrm{~s}, 3 \mathrm{H} \times 2), 3.47(\mathrm{~m}, 2 \mathrm{H} \times 2), 3.32,3.30,3.28,3.26(\mathrm{~s}, 3 \mathrm{H} \times 4)$, 2.56, $2.55(\mathrm{~s}, 1 \mathrm{H} \times 2), 2.01-2.20(\mathrm{~m}, 6 \mathrm{H} \times 2), 1.62-1.78(\mathrm{~m}, 5 \mathrm{H} \times 2), 1.46-1.60(\mathrm{~m}, 5 \mathrm{H} \times$ 2), $1.42(\mathrm{~s}, 3 \mathrm{H} \times 2), 1.35(\mathrm{~s}, 3 \mathrm{H} \times 2), 1.25,1.16(\mathrm{~d}, J=5.4 \mathrm{~Hz}, 3 \mathrm{H} \times 2), 0.93,0.91(\mathrm{~d}, J=$ $6.6 \mathrm{~Hz}, 3 \mathrm{H} \times 2), 0.85,0.82(\mathrm{~d}, J=7.0 \mathrm{~Hz}, 3 \mathrm{H} \times 2) ;{ }^{13} \mathbf{C} \mathbf{~ N M R}\left(\mathbf{3 0 0} \mathbf{~ M H z}, \mathbf{C D C l}_{3}\right)$ : (mixture of two diastereomers) $\delta 159.25,138.59,134.38,134.35,134.31,134.24,133.37$, 
$133.34,131.12,130.70,129.30,128.46,127.96,127.88,127.64,126.60,126.54,114.51$, $113.85,108.55,97.45,96.57,96.53,94.89,94.54,85.04,84.76,83.19,79.70,79.60$, $77.43,77.08,77.08,74.12,72.00,71.99,71.23,71.08,71.02,70.98,69.87,69.69,66.63$, $55.87,55.81,55.75,55.37,40.57,40.54,38.58,38.45,38.30,37.40,37.16,36.05,36.01$, $29.35,29.30,28.96,28.93,28.49,28.38,26.82,25.49,23.34,23.32,14.58,10.61,10.58$;

HRMS: calcd for $\mathrm{C}_{54} \mathrm{H}_{78} \mathrm{O}_{11} \mathrm{Si}\left[\mathrm{MNa}^{+}\right] \mathrm{m} / z$ 953.5211, found 953.5242 .

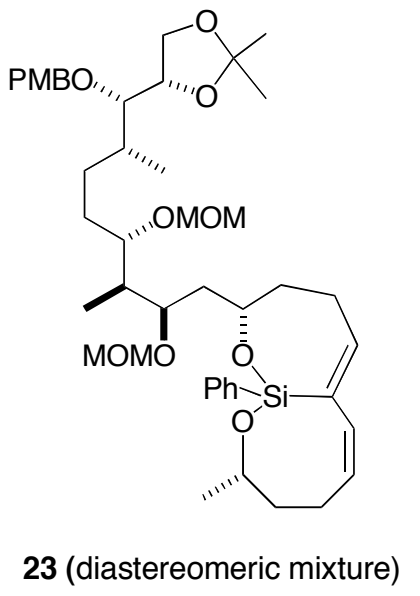

To a solution of silaketal $22(129 \mathrm{mg}, 0.14 \mathrm{mmol})$ in dry $\mathrm{CH}_{2} \mathrm{Cl}_{2}$, flushed with $\mathrm{N}_{2}$, was added Grubb's second-generation catalyst (10 mg, $8.5 \mathrm{~mol} \%)$. The solution was refluxed under $\mathrm{N}_{2}$ atmosphere for $2 \mathrm{~h}\left(\mathrm{R}_{\mathrm{f}}=0.6\right.$ for both starting material and product, 3:1 hexanes:ethyl acetate). The solution was stirred at room temperature in open atmosphere for $1 \mathrm{~h}$, at which point it was concentrated in vacuo. The brown residue was purified by silica gel column chromatography (5:1 to 4:1 hexane:ethyl acetate) to afford $91 \mathrm{mg}$ (84 \%) of bicycle 23 as a colorless oil; ${ }^{1} \mathbf{H}$ NMR (300 $\mathbf{~ M H z}, \mathbf{C D C l}_{3}$ ): (mixture of two diastereomers) $\delta$ 7.58-7.67 (m, $2 \mathrm{H} \times 2), 7.32-7.41(\mathrm{~m}, 3 \mathrm{H} \times 2), 7.22-7.27(\mathrm{~m}, 2 \mathrm{H} \times 2)$, $6.86(\mathrm{~m}, 2 \mathrm{H} \times 2), 6.50(\mathrm{t}, J=7.9 \mathrm{~Hz}, 1 \mathrm{H} \times 2), 6.28,6.25(\mathrm{~d}, J=11.6 \mathrm{~Hz}, 1 \mathrm{H} \times 2), 5.26-$ $5.48(\mathrm{~m}, 1 \mathrm{H} \times 2), 5.00(\mathrm{~d}, J=6.7 \mathrm{~Hz}, 1 \mathrm{H}), 4.54-4.74(\mathrm{~m}, 5 \mathrm{H} \times 2), 4.40(\mathrm{~m}, 1 \mathrm{H}), 4.12-$ $4.22(\mathrm{~m}, 1 \mathrm{H} \times 2), 4.15(\mathrm{~m}, 1 \mathrm{H}), 4.02(\mathrm{dd}, J=7.9,6.4 \mathrm{~Hz}, 1 \mathrm{H} \times 2), 3.88-3.93(\mathrm{~m}, 2 \mathrm{H} \times 2)$, $3.79(\mathrm{~s}, 3 \mathrm{H} \times 2), 3.42-3.60(\mathrm{~m}, 2 \mathrm{H} \times 2), 3.39,3.37,3.36,3.27$, (s, $3 \mathrm{H} \times 4), 2.06-2.57(\mathrm{~m}$, $4 \mathrm{H} \times 2), 1.53-1.99(\mathrm{~m}, 10 \mathrm{H} \times 2), 1.28-1.50(\mathrm{~m}, 2 \mathrm{H} \times 2), 1.42(\mathrm{~s}, 3 \mathrm{H} \times 2), 1.35(\mathrm{~s}, 3 \mathrm{H} \times$ 2), $1.25,1.09(\mathrm{~d}, J=6.2 \mathrm{~Hz}, 3 \mathrm{H} \times 2), 0.96,0.95(\mathrm{~d}, J=6.0 \mathrm{~Hz}, 3 \mathrm{H} \times 2), 0.86,0.84(\mathrm{~d}, J=$ $6.0 \mathrm{~Hz}, 3 \mathrm{H} \times 2) ;{ }^{13} \mathbf{C} \mathbf{N M R}\left(\mathbf{3 0 0} \mathbf{~ M H z}, \mathbf{C D C l}_{3}\right)$ : (mixture of two diastereomers) $\delta 159.25$, 
$154.28,146.08,138.68,136.82,135.99,135.56,134.35,134.26,134.07,134.00,132.46$, $131.16,130.28,129.98,129.32,129.15,128.02,127.99$, 125.93, 113.85, 108.56, 98.51, $97.33,96.85,96.73,83.18,79.68,79.63,77.84,77.35,74.16,70.55,68.96,68.18,66.64$, 65.88, 56.11, 56.04, 55.79, 55.78, 55.38, 41.01, 40.47, 38.90, 38.34, 37.29, 36.99, 36.10, $35.07,29.69,29.62,28.77,28.65,27.48,26.83,26.41,25.51,24.99,24.54,23.73,23.66$, 14.60, 10.49, 10.45; HRMS: calcd for $\mathrm{C}_{44} \mathrm{H}_{66} \mathrm{O}_{10} \mathrm{Si}\left[\mathrm{MNa}^{+}\right] \mathrm{m} / \mathrm{z}$ 805.4323, found 805.4320 .

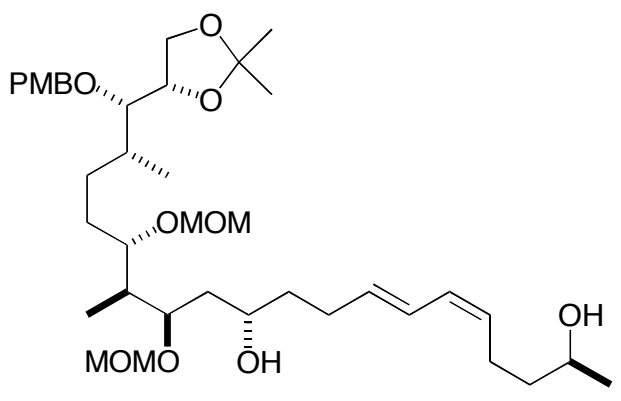

24

To a solution of 23 (45 mg, $0.06 \mathrm{mmol})$ in THF $(1.7 \mathrm{~mL})$ under $\mathrm{N}_{2}$ atmosphere, was added TBAF (tetrabutylammonium fluoride, $0.1 \mathrm{M}, 0.17 \mathrm{mmol}$ ). The solution was stirred at room temperature for $3 \mathrm{~h}$, at which point it was quenched with saturated aqueous $\mathrm{NH}_{4} \mathrm{Cl}$ and diluted with ethyl acetate. The organic layer was separated, washed with water, brine, dried over $\mathrm{MgSO}_{4}$, and filtered. The solution was concentrated in vacuo to give a yellow residue, which was purified by silica gel column chromatography (3:1 hexane:ethyl acetate to $100 \%$ ethyl acetate) to afford $23 \mathrm{mg}(59 \%)$ of diol 24 as a colorless oil; ${ }^{1} \mathbf{H}$ NMR (300 MHz, $\mathbf{C D C l}_{3}$ ): $\delta 7.25$ (m, 2H), 6.87 (m, 2H), 6.37 (dd, $J=$ $11.1,14.3 \mathrm{~Hz}, 1 \mathrm{H}), 5.97(\mathrm{t}, J=11.1,1 \mathrm{H}), 5.69(\mathrm{~m}, 1 \mathrm{H}), 5.31(\mathrm{dd}, J=7.7,18.3 \mathrm{~Hz}, 1 \mathrm{H})$, 4.51-4.67 (overlapping doublets, $6 \mathrm{H}), 4.15(\mathrm{~m}, 1 \mathrm{H}), 4.02(\mathrm{dd}, J=6.3,7.7 \mathrm{~Hz}, 1 \mathrm{H}), 3.90$ (m, 1H), 3.83-3.98 (m, 3H), 3.80 (s, 3H), 3.48 (m, 2H), 3.39 (s, 3H), 3.37 (s, 3H), 3.04 (d, $J=3.4 \mathrm{~Hz}, 1 \mathrm{H}), 2.25(\mathrm{~m}, 4 \mathrm{H}), 2.01(\mathrm{~m}, 1 \mathrm{H}), 1.72(\mathrm{~m}, 1 \mathrm{H}), 1.38-1.67(\mathrm{~m}, 10 \mathrm{H}), 1.42(\mathrm{~s}$, $3 \mathrm{H}), 1.35$ (s, 3H), 1.20 (d, $J=6.8 \mathrm{~Hz}, 3 \mathrm{H}), 0.94$ (d, $J=7.2 \mathrm{~Hz}, 3 \mathrm{H}), 0.84$ (d, $J=7.0 \mathrm{~Hz}$, 3H); ${ }^{13} \mathbf{C}$ NMR (300 MHz, $\left.\mathbf{C D C l}_{3}\right): \delta 159.28,134.69,129.40,129.32,129.25,125.88$, 113.86, 108.61, 96.76, 96.43, 82.96, 79.61, 77.06, 76.67, 74.04, 67.66, 67.30, 66.68, $56.21,56.03,55.38,39.97,39.07,37.64,37.27,36.00,29.30,29.17,28.93,26.81,25.45$, 
24.23, 23.72, 14.69, 10.54; HRMS: calcd for $\mathrm{C}_{38} \mathrm{H}_{64} \mathrm{O}_{10}\left[\mathrm{MNa}^{+}\right] \mathrm{m} / \mathrm{z}$ 703.4397, found 703.4380 . 
<smiles>C=CC(C)C(OCCC)C([18OH])C1COC(C)(C)O1</smiles>
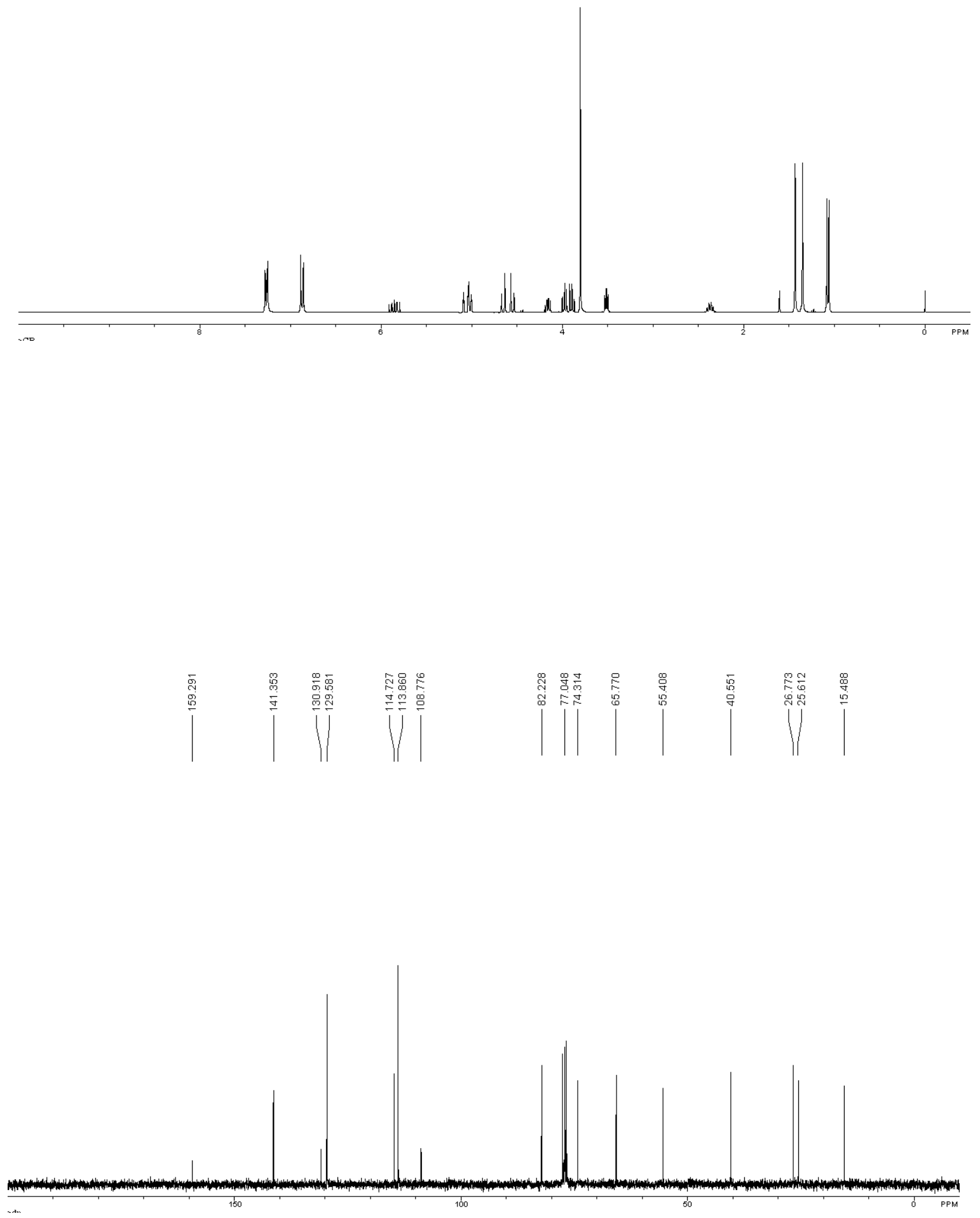


$$
\left.\overbrace{\mathrm{O}}^{\mathrm{O}}\right|_{\mathrm{OH}} ^{\mathrm{OPMB}}
$$
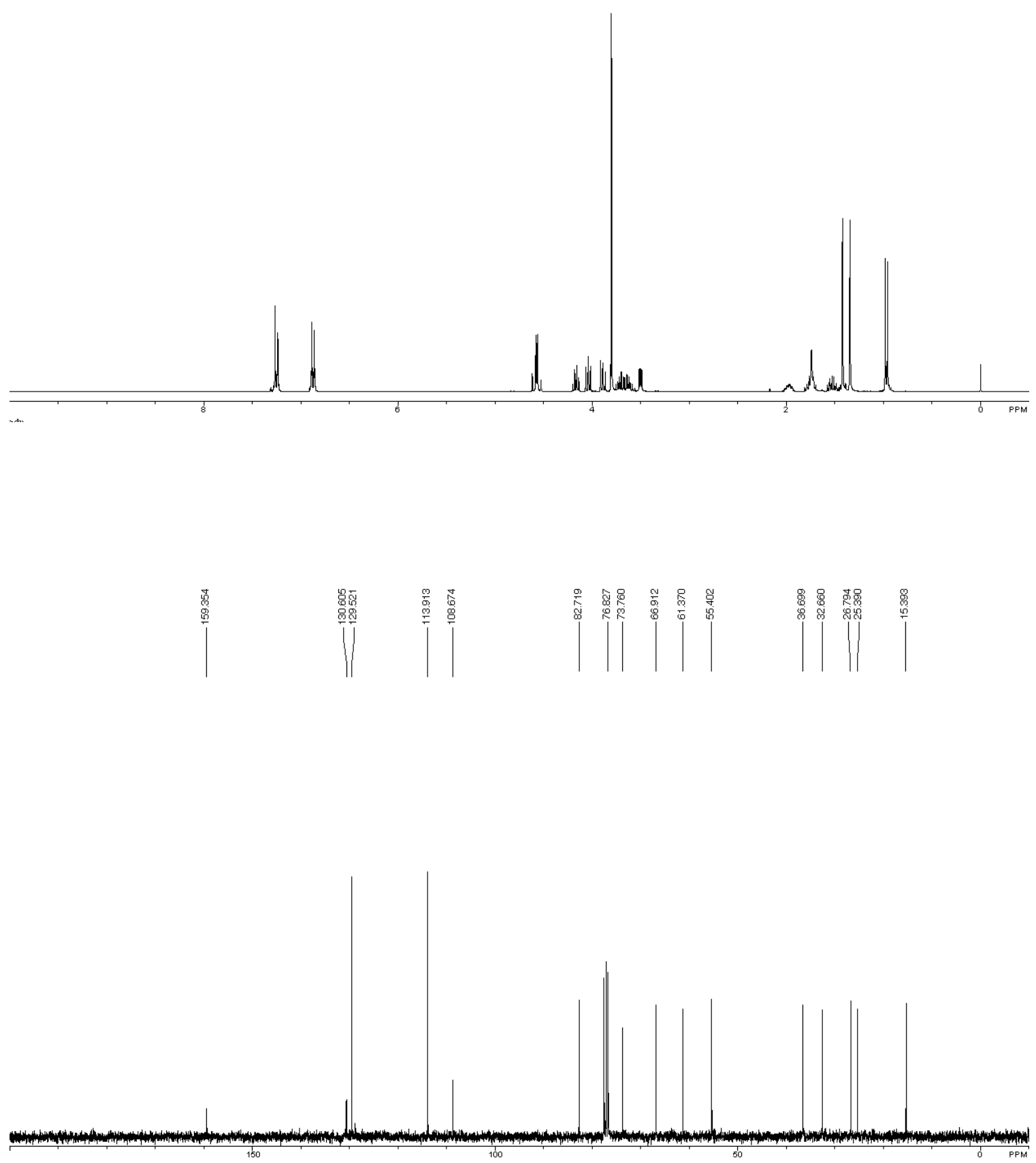


$$
\overbrace{0}^{O P M B}
$$
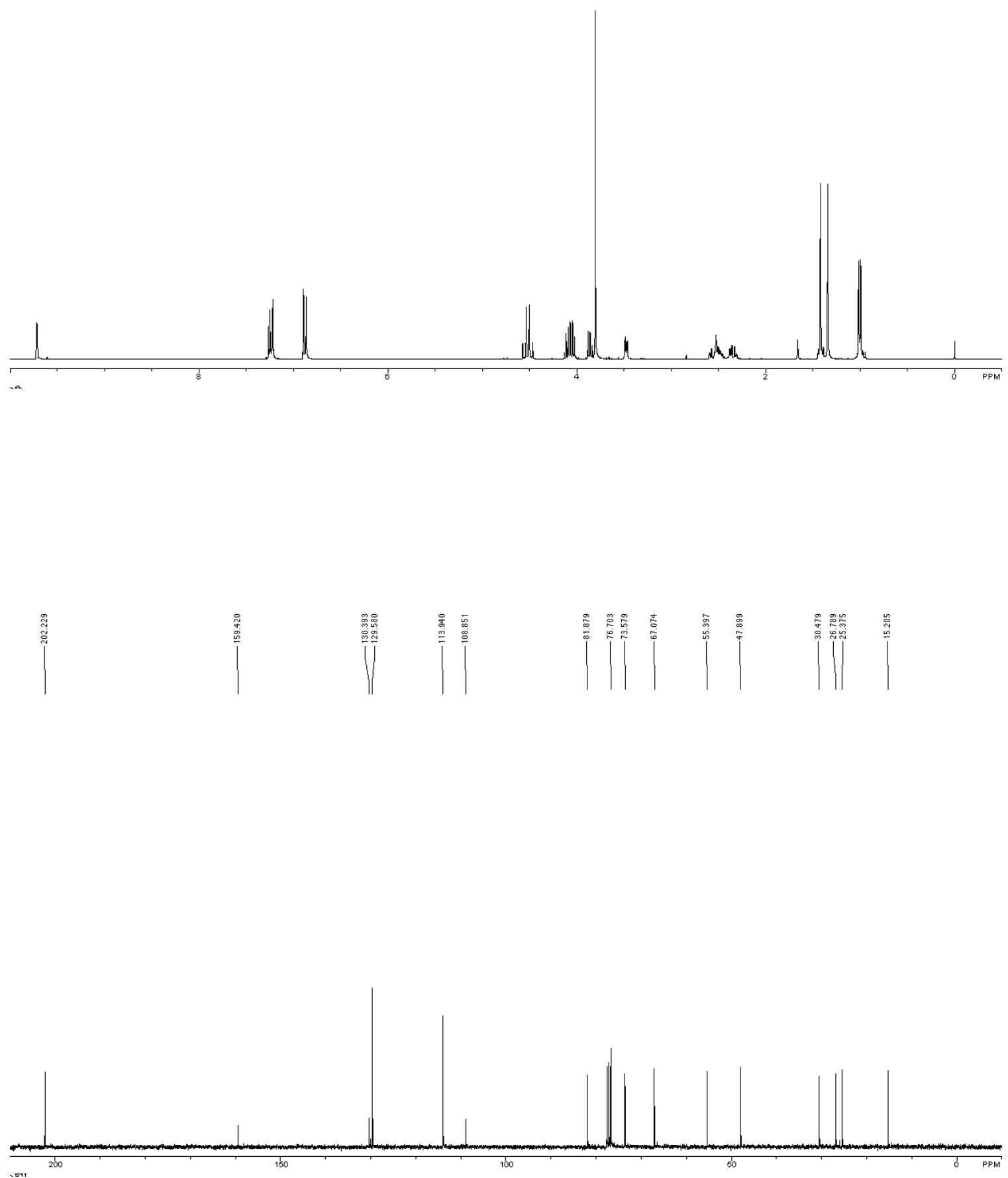

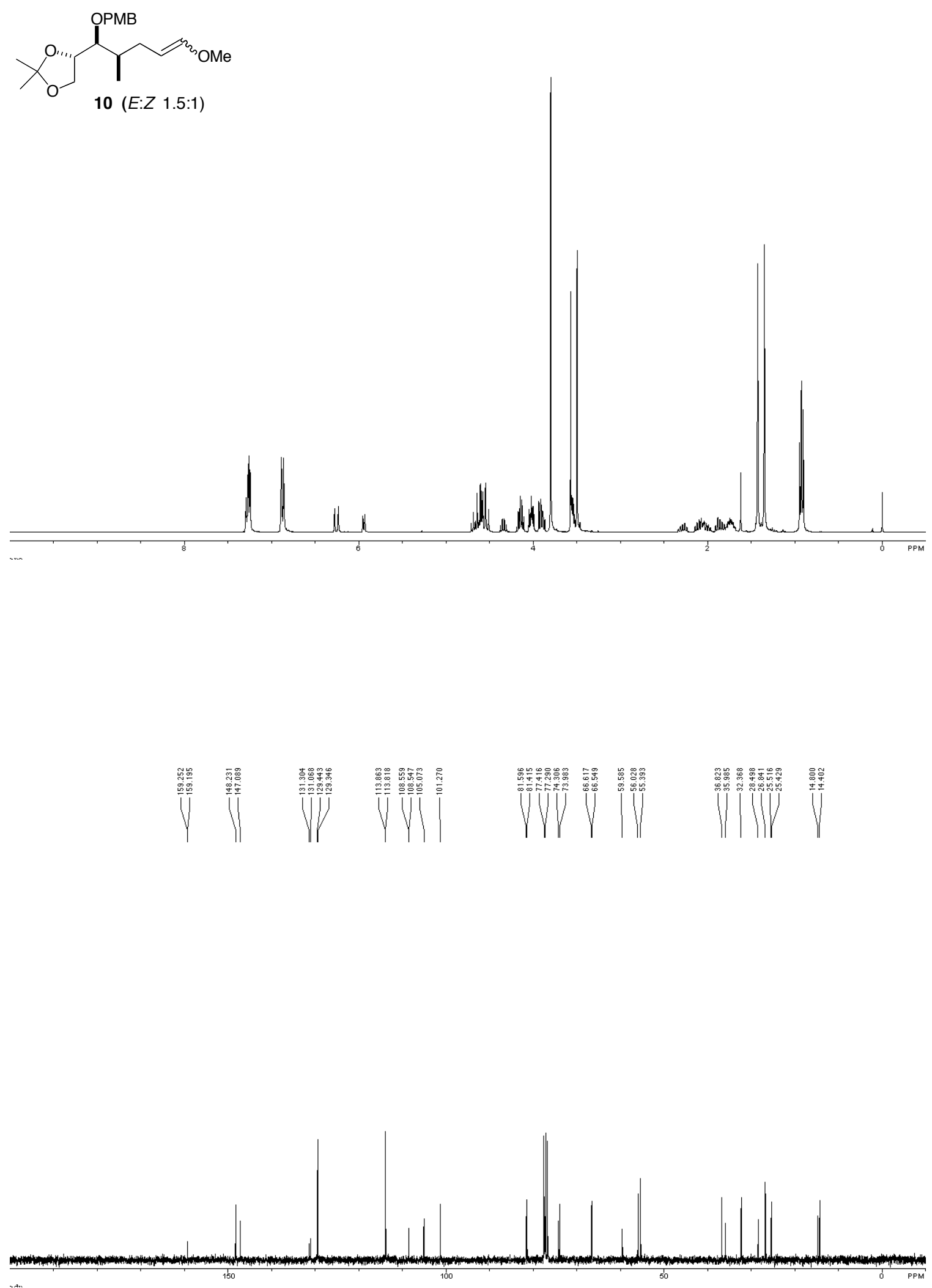

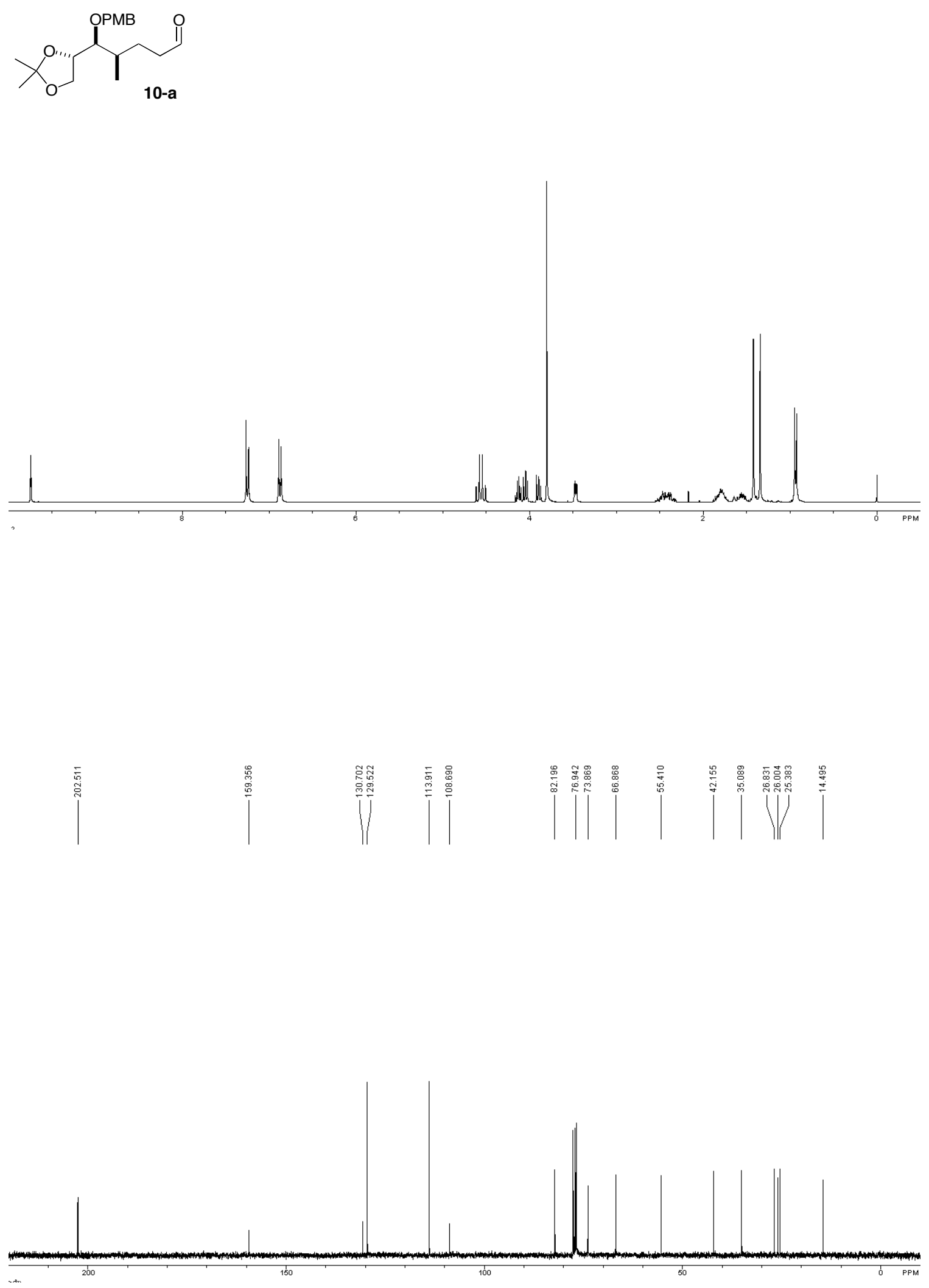

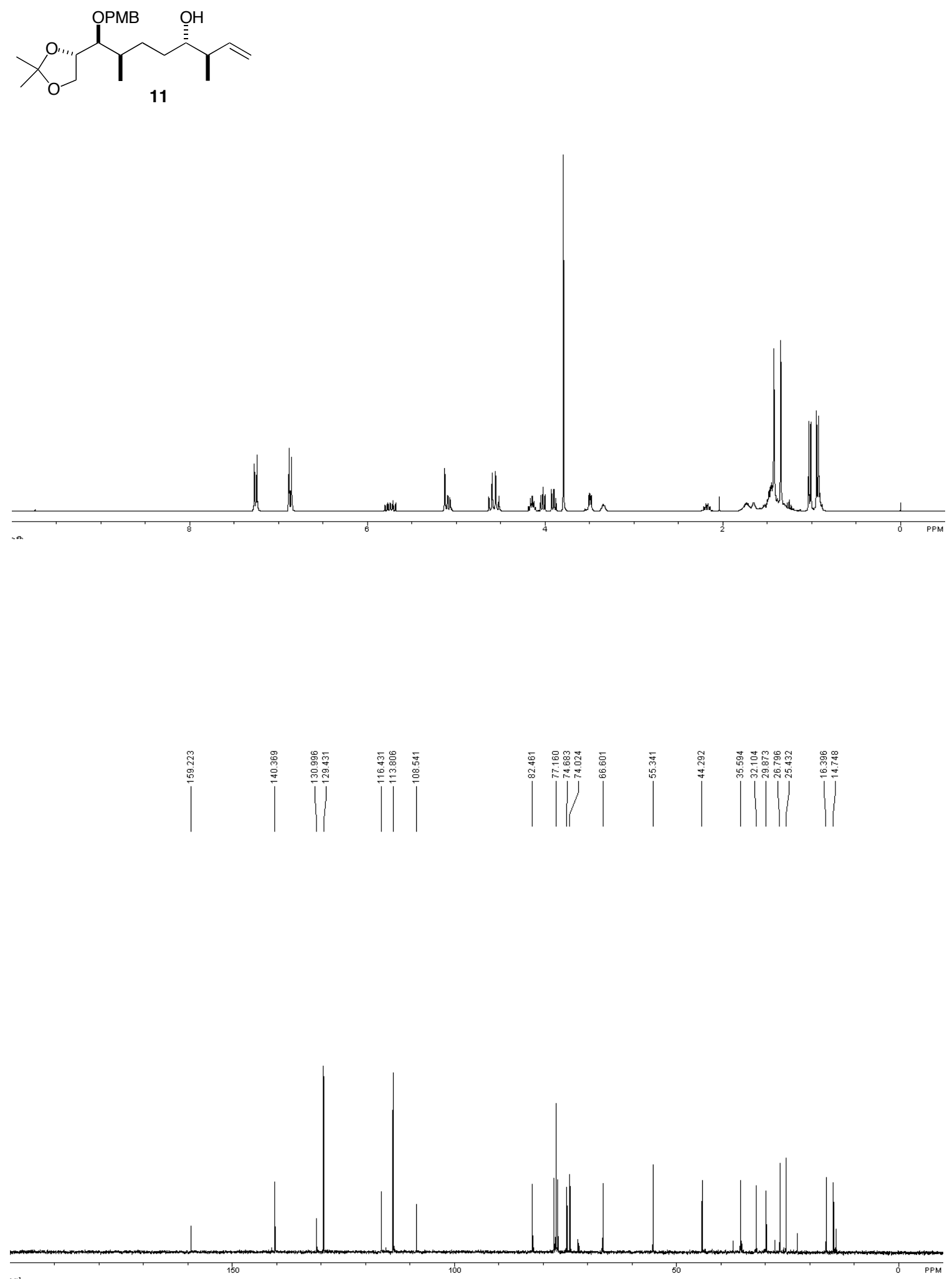

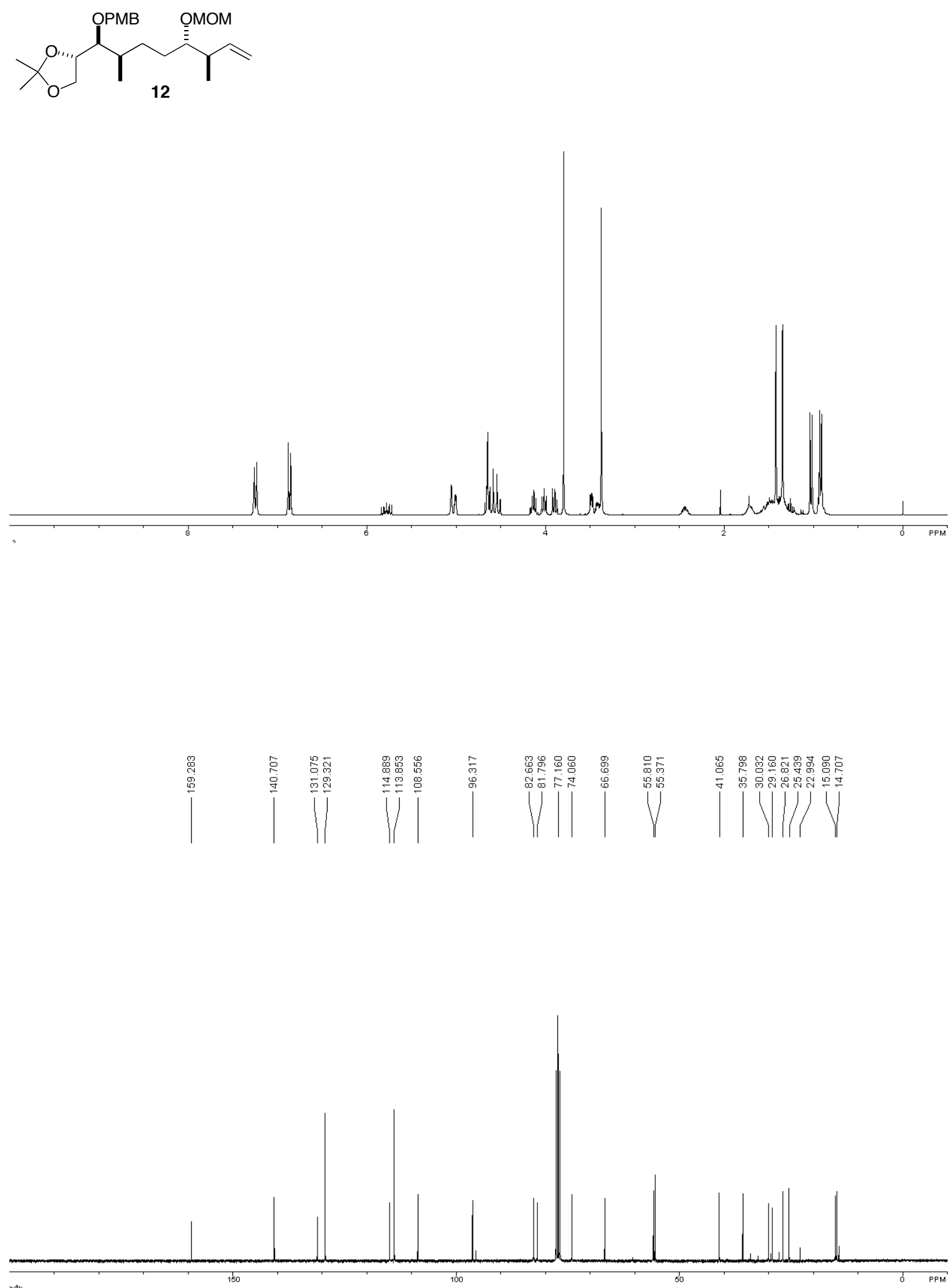

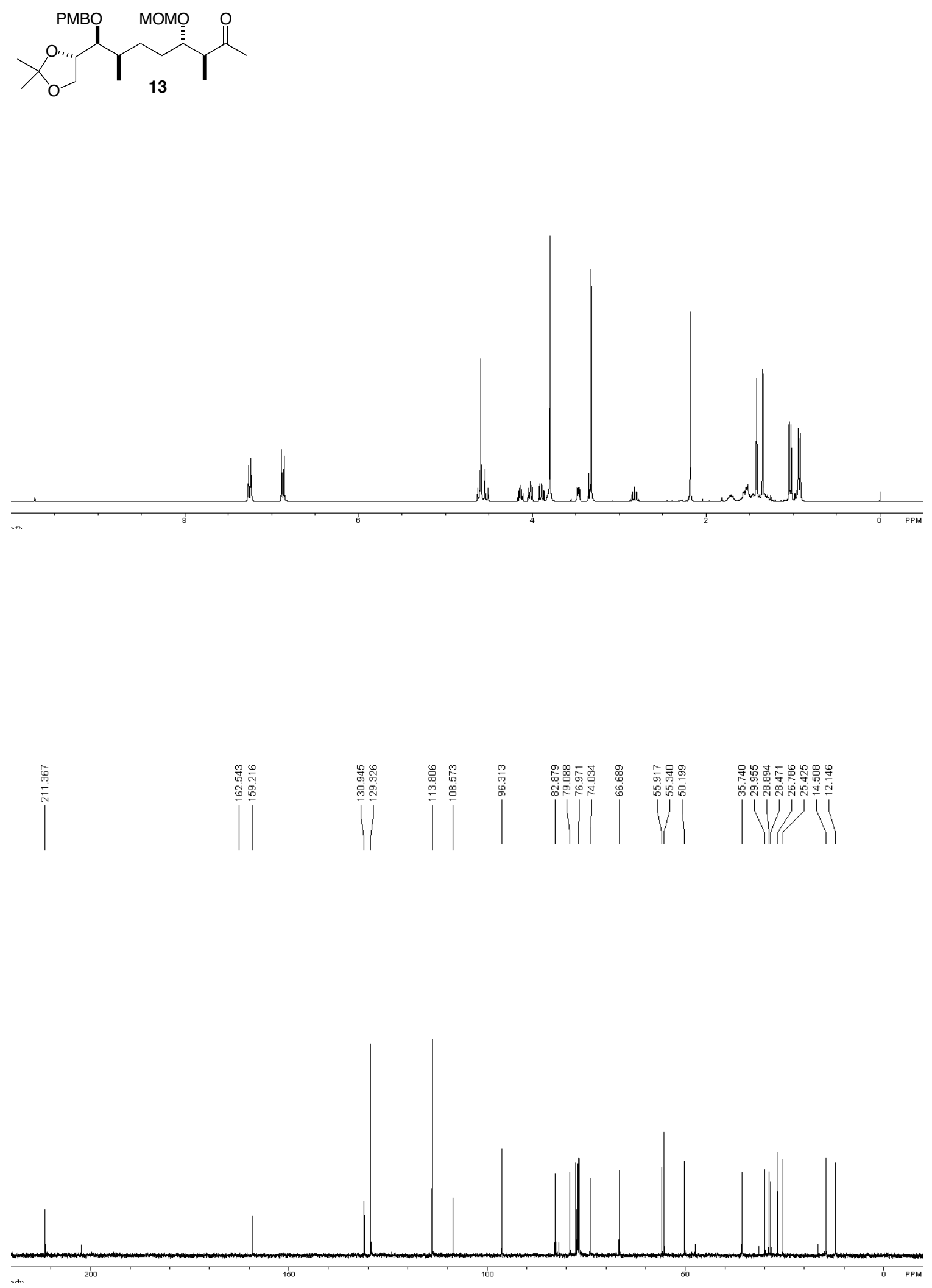


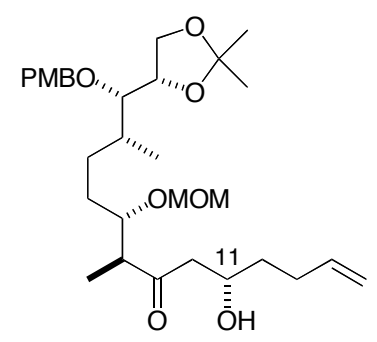

18 (and 11-epimer, 86:14)
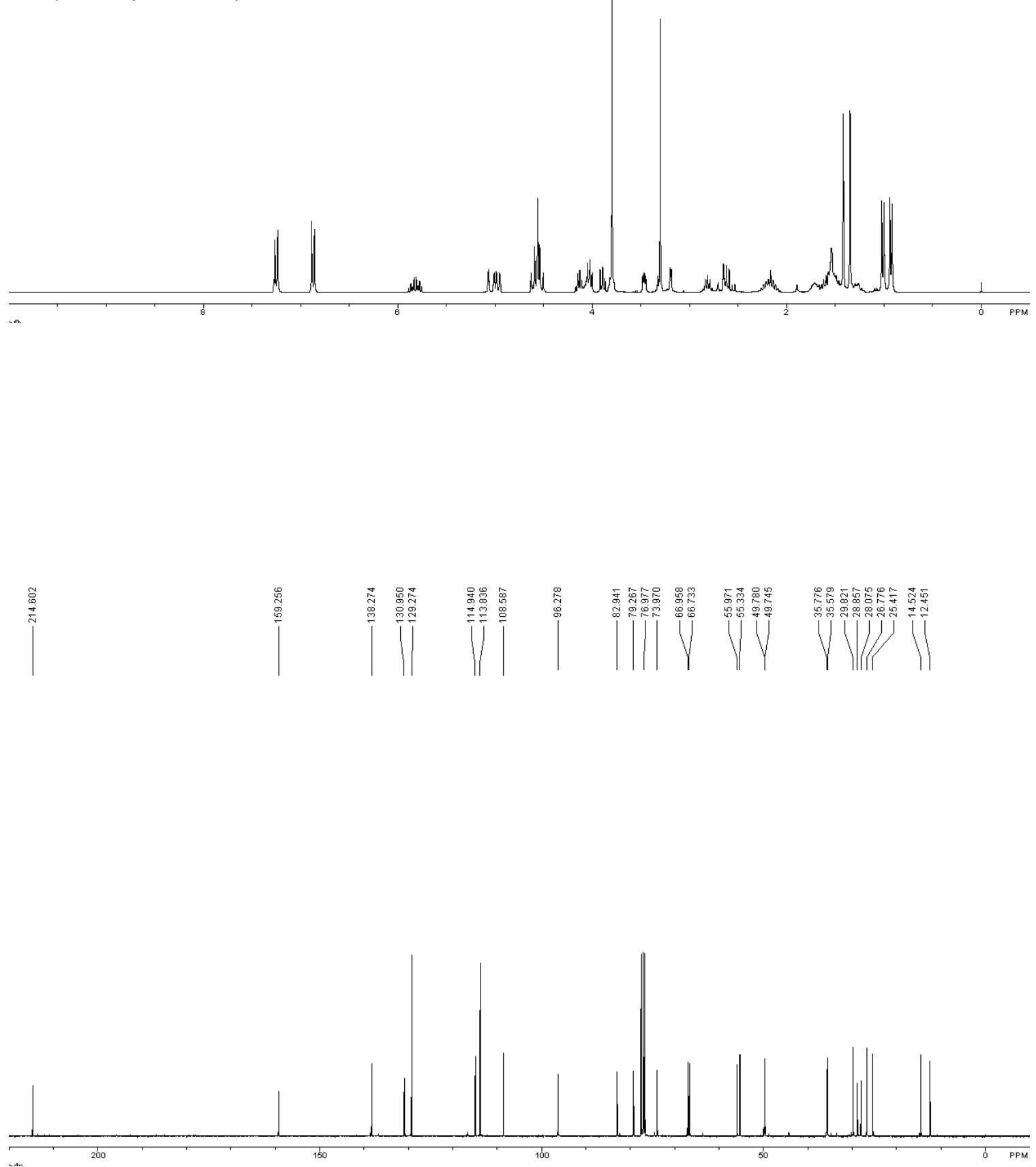


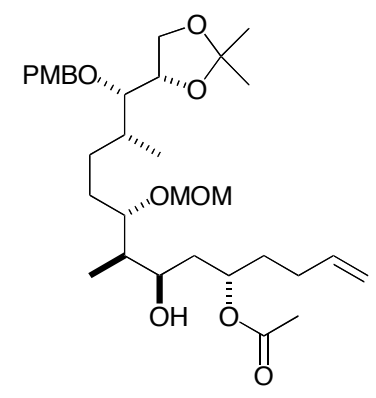

19
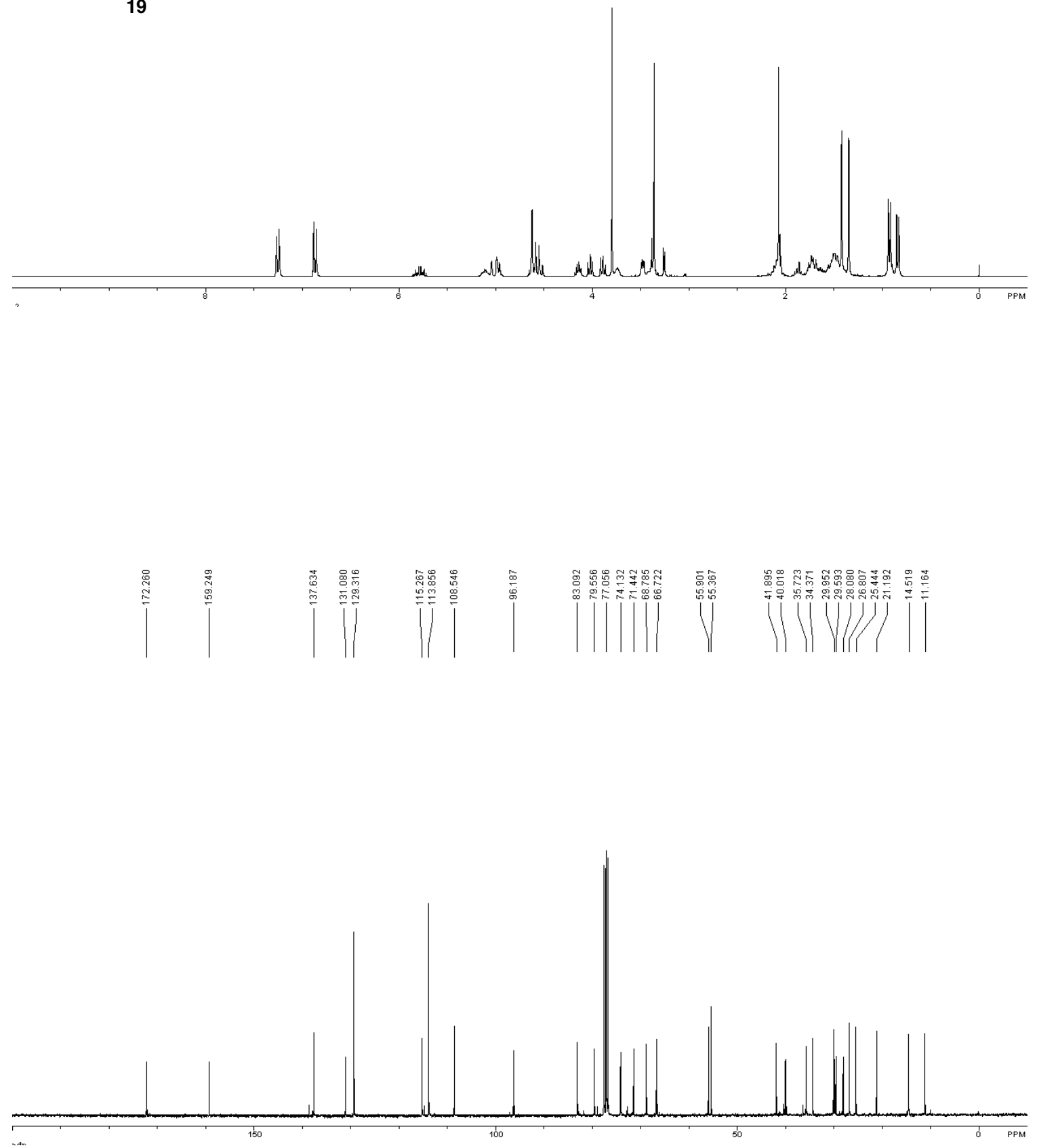

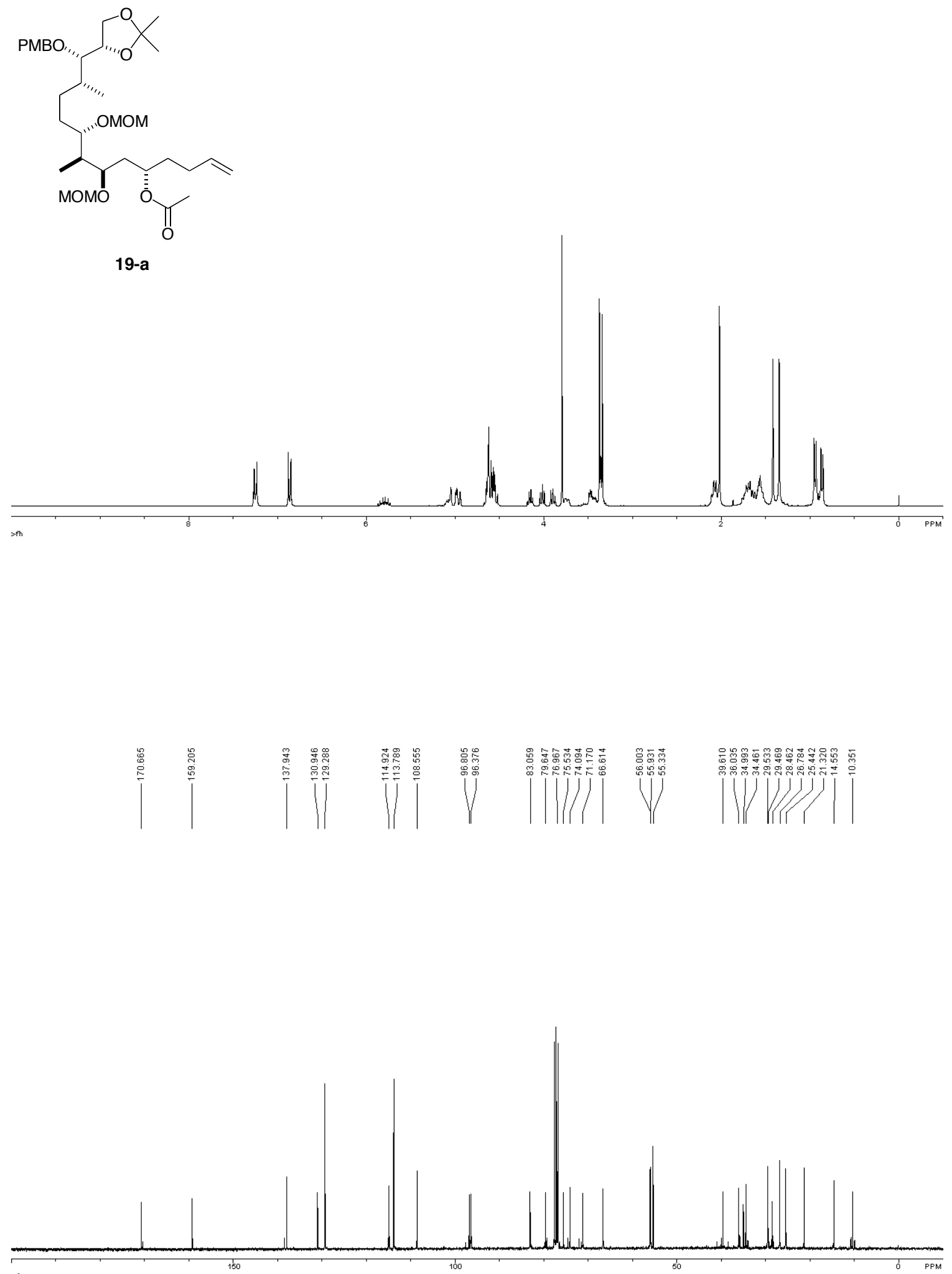

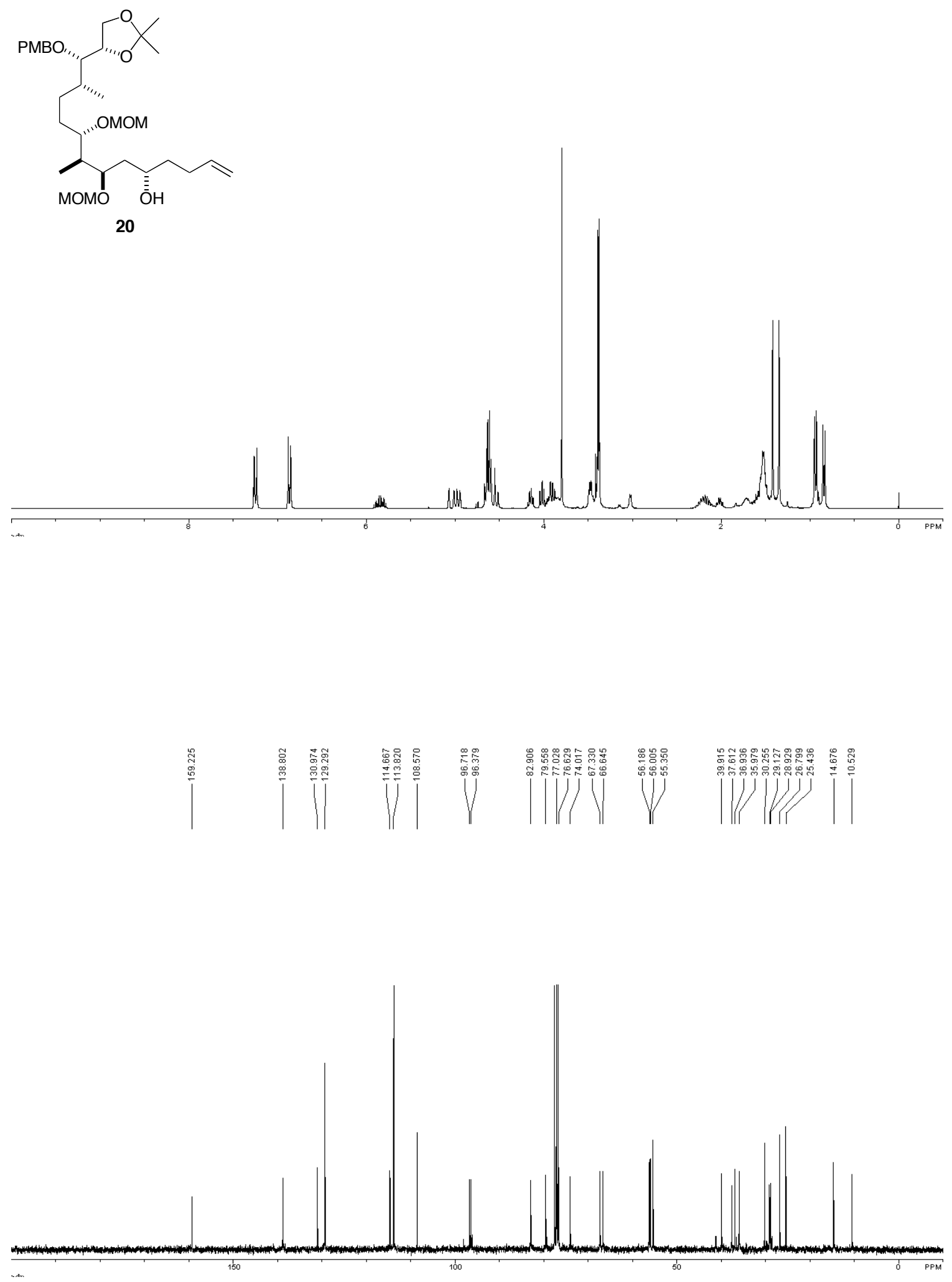


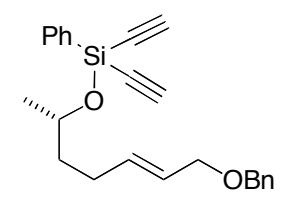

21
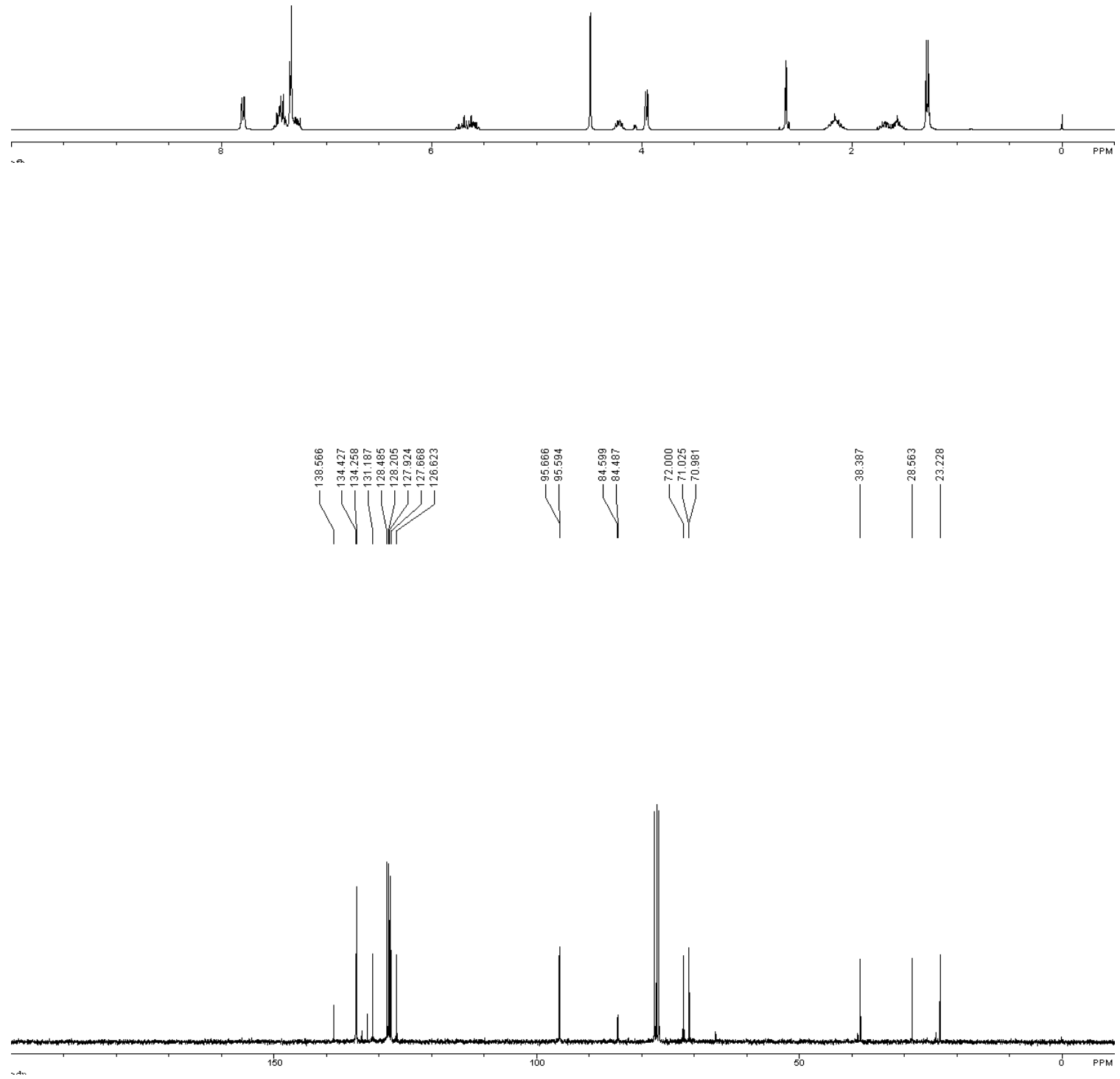


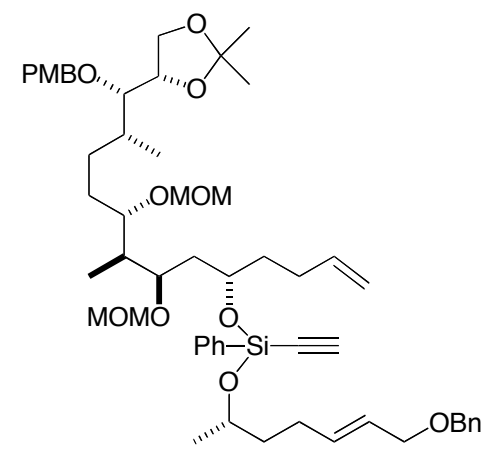

22 (diastereomeric mixture)
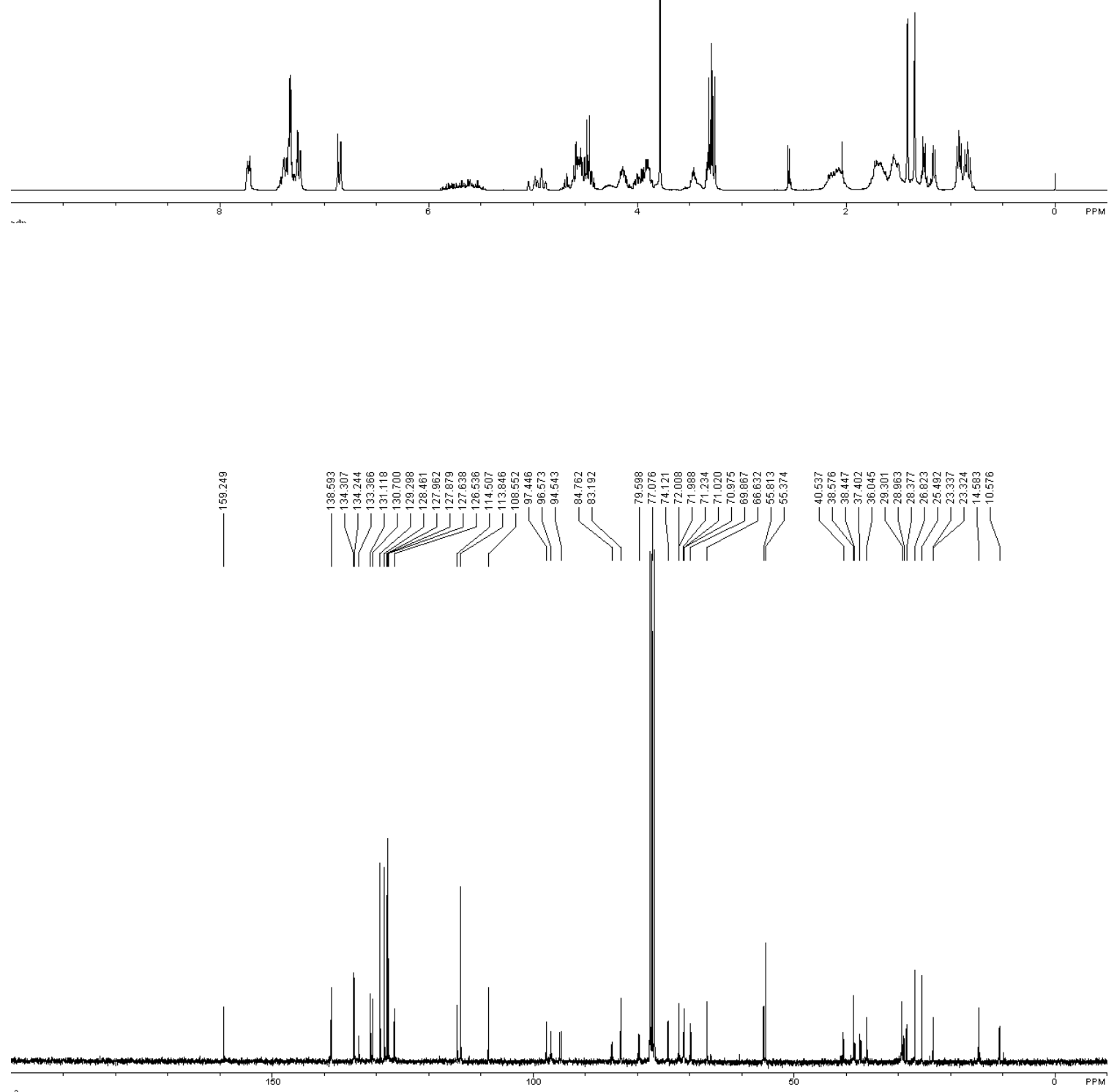


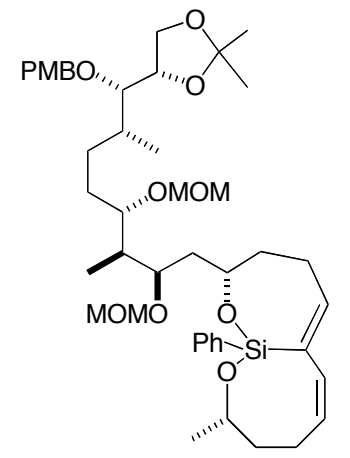

23 (diastereomeric mixture)
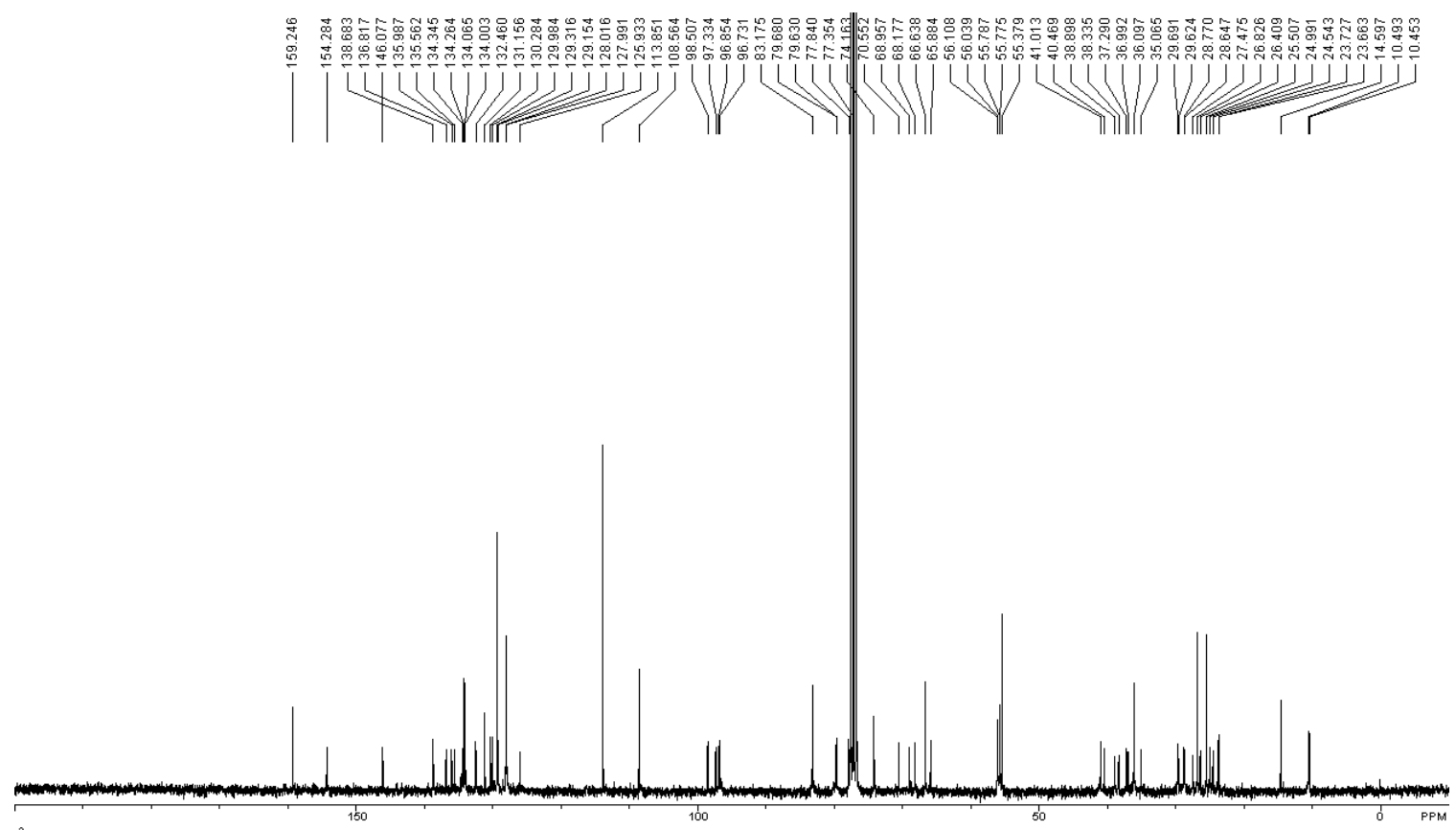

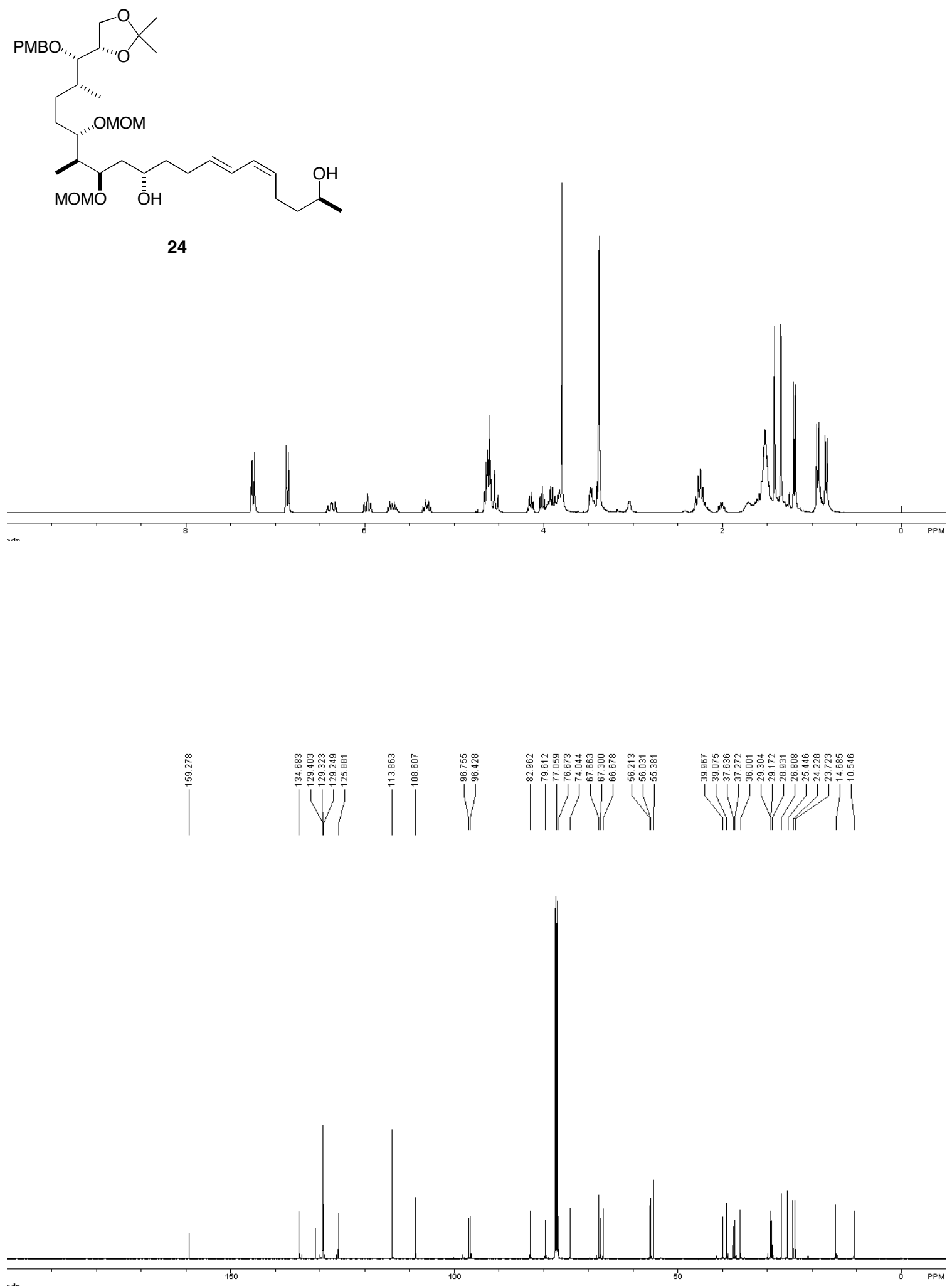